\title{
Oncolytic viruses encoding bispecific $T$ cell engagers: a blueprint for emerging immunovirotherapies
}

\author{
Johannes P. W. Heidbuechel ${ }^{1}$ and Christine E. Engeland ${ }^{1,2,3^{*}}$ (D)
}

\begin{abstract}
Bispecific T cell engagers (BiTEs) are an innovative class of immunotherapeutics that redirect $T$ cells to tumor surface antigens. While efficacious against certain hematological malignancies, limited bioavailability and severe toxicities have so far hampered broader clinical application, especially against solid tumors. Another emerging cancer immunotherapy are oncolytic viruses (OVs) which selectively infect and replicate in malignant cells, thereby mediating tumor vaccination effects. These oncotropic viruses can serve as vectors for tumor-targeted immunomodulation and synergize with other immunotherapies. In this article, we discuss the use of OVs to overcome challenges in BiTE therapy. We review the current state of the field, covering published preclinical studies as well as ongoing clinical investigations. We systematically introduce OV-BiTE vector design and characteristics as well as evidence for immunestimulating and anti-tumor effects. Moreover, we address additional combination regimens, including CART cells and immune checkpoint inhibitors, and further strategies to modulate the tumor microenvironment using OV-BiTEs. The inherent complexity of these novel therapeutics highlights the importance of translational research including correlative studies in early-phase clinical trials. More broadly, OV-BiTEs can serve as a blueprint for diverse OV-based cancer immunotherapies.
\end{abstract}

Keywords: Bispecific T cell engagers, Oncolytic viruses, Cancer immunotherapy, CART cells, Viral vectors, Immune checkpoint blockade, Adenovirus, Vaccinia virus, Measles virus, Tumor microenvironment

\section{Background}

The strong rationale for combining BiTEs with oncolytic viruses

Bispecific $\mathrm{T}$ cell engagers (BiTEs) represent a novel class of immunotherapeutic agents. BiTEs are fusion proteins that consist of two antibody single-chain variable fragments (scFv) with one scFv binding $\mathrm{CD} 3$ and the second scFv binding a tumor surface antigen. BiTE binding

*Correspondence: christine.engeland@nct-heidelberg.de; christine. engeland@uni-wh.de

${ }^{1}$ Research Group Mechanisms of Oncolytic Immunotherapy, Clinical Cooperation Unit Virotherapy, German Cancer Research Center (DKFZ), National Center for Tumor Diseases (NCT), University Hospital Heidelberg, Heidelberg, Germany

Full list of author information is available at the end of the article redirects polyclonal $\mathrm{T}$ cells toward tumor cells independent of MHC, thereby inducing anti-tumor cytotoxicity even at low concentrations. This approach has demonstrated considerable clinical efficacy against hematological malignancies. Blinatumomab, a CD3xCD19 BiTE, has been approved for treatment of $\mathrm{B}$ cell malignancies (reviewed in [1]). However, due to limited serum half-life, continuous infusion is required. Systemic administration is associated with severe, potentially fatal toxicities. Efficacy against solid tumors has been limited, owing to physical barriers and an immunosuppressive tumor microenvironment (reviewed in [2,3]). As such, BiTEs are representative for diverse emerging cancer immunotherapeutics which show remarkable efficacy in certain original author(s) and the source, provide a link to the Creative Commons licence, and indicate if changes were made. The images or other third party material in this article are included in the article's Creative Commons licence, unless indicated otherwise in a credit line to the material. If material is not included in the article's Creative Commons licence and your intended use is not permitted by statutory regulation or exceeds the permitted use, you will need to obtain permission directly from the copyright holder. To view a copy of this licence, visit http://creativecommons.org/licenses/by/4.0/. The Creative Commons Public Domain Dedication waiver (http://creativeco mmons.org/publicdomain/zero/1.0/) applies to the data made available in this article, unless otherwise stated in a credit line to the data. 
subgroups of patients, but limited efficacy and unacceptable toxicities for the most part $[4,5]$.

One strategy to overcome these limitations has gained widespread interest in the immunotherapy field: oncolytic viruses (OVs). OVs selectively infect and replicate in malignant cells, ultimately leading to tumor cell lysis. This selectivity is shared between OVs across different virus families (for a concise comparison of clinically advanced oncolytic virus platforms, see Table 1) [48]. Oncolytic virotherapy relies on tumor cell-specific changes associated with the hallmarks of cancer, including increased receptor expression, impaired antiviral response, and altered metabolism (reviewed in [49]). OV replication is thus restricted to the tumor site, leaving healthy tissue unharmed (reviewed in [50]). In addition to direct tumor debulking via lytic replication, OVs can induce stromal remodeling [51], exert anti-angiogenic effects [52,53], and, most prominently, evoke anti-tumor immune responses (reviewed in [54, 55]). Immunogenic cell death with release of tumor-associated antigens (TAAs), danger- and pathogen-associated molecular patterns (DAMPs and PAMPs) as well as cytokines and chemokines in the course of infection promote tumorspecific immunity (reviewed in [56]). OV-mediated APC maturation and antigen (cross-)presentation can result in systemic anti-tumor immunity via priming, activation, proliferation, trafficking, memory formation, cytokine release, and cytotoxic activity of polyclonal $\mathrm{T}$ cells. Oncolytic virotherapy is therefore an immunotherapy in its own right and has ideal properties for combinatorial approaches (reviewed in [57-59]). The unique, multipronged mechanism of action circumvents the development of resistance to classical therapies. Furthermore, oncolysis can also render immune-excluded and immunosuppressed tumors sensitive to otherwise unsuccessful strategies such as immune checkpoint inhibition [60-62]. Finally, OVs can be engineered to express immunotherapeutic transgenes directly at the site of infection, i.e., the inflamed tumor, achieving high local concentrations while preventing systemic side effects (reviewed in [57]). By retargeting of OVs on the entry- or post entry-level, improved tissue specificity can be achieved to further reduce the risk of immunotherapeutic on-target, offtumor toxicities [50]. The first FDA- and EMA-approved oncolytic virus, talimogene laherparepvec (T-VEC), a modified herpes simplex virus for the treatment of malignant melanoma, encodes GM-CSF for enhanced in situ tumor vaccination and represents the current clinical benchmark in the field (reviewed in [63]). Recent data from clinical practice indicate high rates of response to T-VEC [64]. However, mainly patients with early-stage disease benefit. Therefore, combination therapy may be required to fully exploit the potential of oncolytic virotherapy. Furthermore, anti-tumor $\mathrm{T}$ cell activity has been associated with favorable outcome [30, 65, 66].

Accordingly, the combination of BiTEs and OVs promises mutual benefits (see schematic in Fig. 1): OV infection induces local inflammation and attracts $\mathrm{T}$ cells to tumors, which can be redirected to tumor cells by BiTEs. In addition, encoding BiTEs in OVs can overcome BiTE limitations. This mode of delivery can maximize local concentrations at the tumor site and support penetration into solid tumors while reducing systemic exposure, thereby increasing the therapeutic window.

Efficacy of the OV-BiTE approach, especially against solid tumors, has been postulated by several groups [67-69] and investigated by a collection of recent preclinical studies. Herein, we review these approaches, focusing on BiTE target selection, transgene design, virus and BiTE characterization in vitro as well as the models used to analyze efficacy of the different BiTE-encoding oncolytic viruses (OV-BiTEs). We first address original research articles about OV-BiTEs, followed by publications featuring OV-BiTE combinations with additional immunotherapeutics. Lastly, we cover literature on OVencoded BiTEs that target tumor-promoting cell types of the microenvironment rather than tumor cells directly. While providing an overview on the existing literature and highlighting the contributions of each publication to the current state of the field, we aim at deducing the most important open questions to be addressed for successful clinical implementation. This review article specifically discusses the existing literature on OVs encoding BiTEs. However, more broadly, OV-BiTEs are an example for the benefit of combining OVs with other immunomodulation strategies for safe and effective cancer immunotherapy. Along these lines, OV-BiTE can serve as a blueprint for development of advanced OV immunotherapeutics.

\section{Preclinical study design}

In general, the publications featured in this review follow a similar structure. This study design is typical for preclinical investigations of immunomodulatory OVs. First, the design of BiTE-encoding vectors is described, and we will highlight the main characteristics of the transgene sequences and expression cassettes in this review (see Fig. 2 for a comparative illustration). Subsequently, the viral vectors and transgene products are characterized. Viral replication kinetics and direct tumor cell killing are assessed by progeny quantification and metabolic-, impedance-, or flow cytometry-based cell viability assays, respectively. BiTE expression and secretion are shown via SDS-PAGE and immunoblotting of cell-free supernatant of virus-infected cells. Binding specificity of BiTEs to their cognate antigens and antigen-expressing cells is assessed by ELISA and/or flow cytometry assays. 


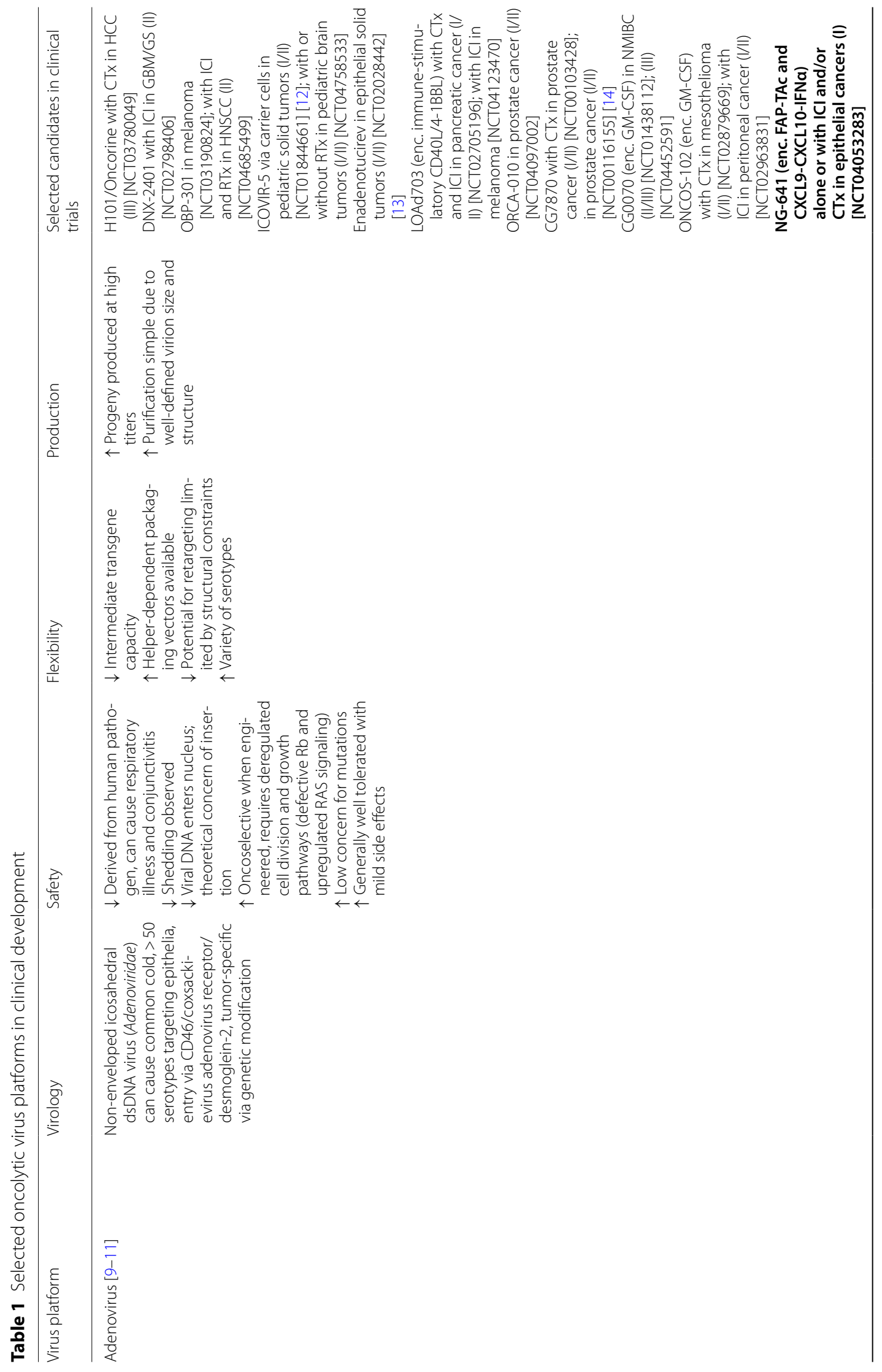




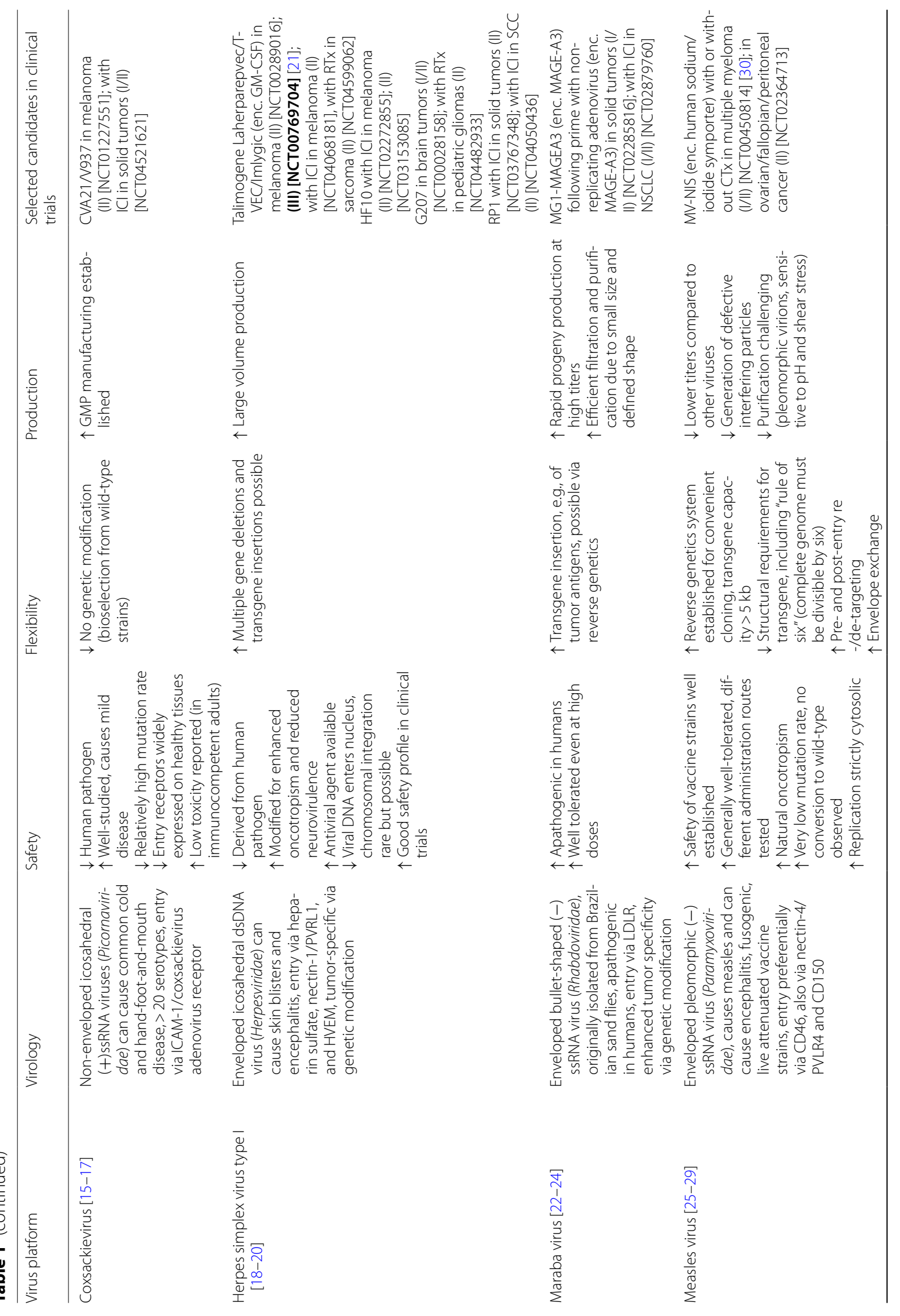




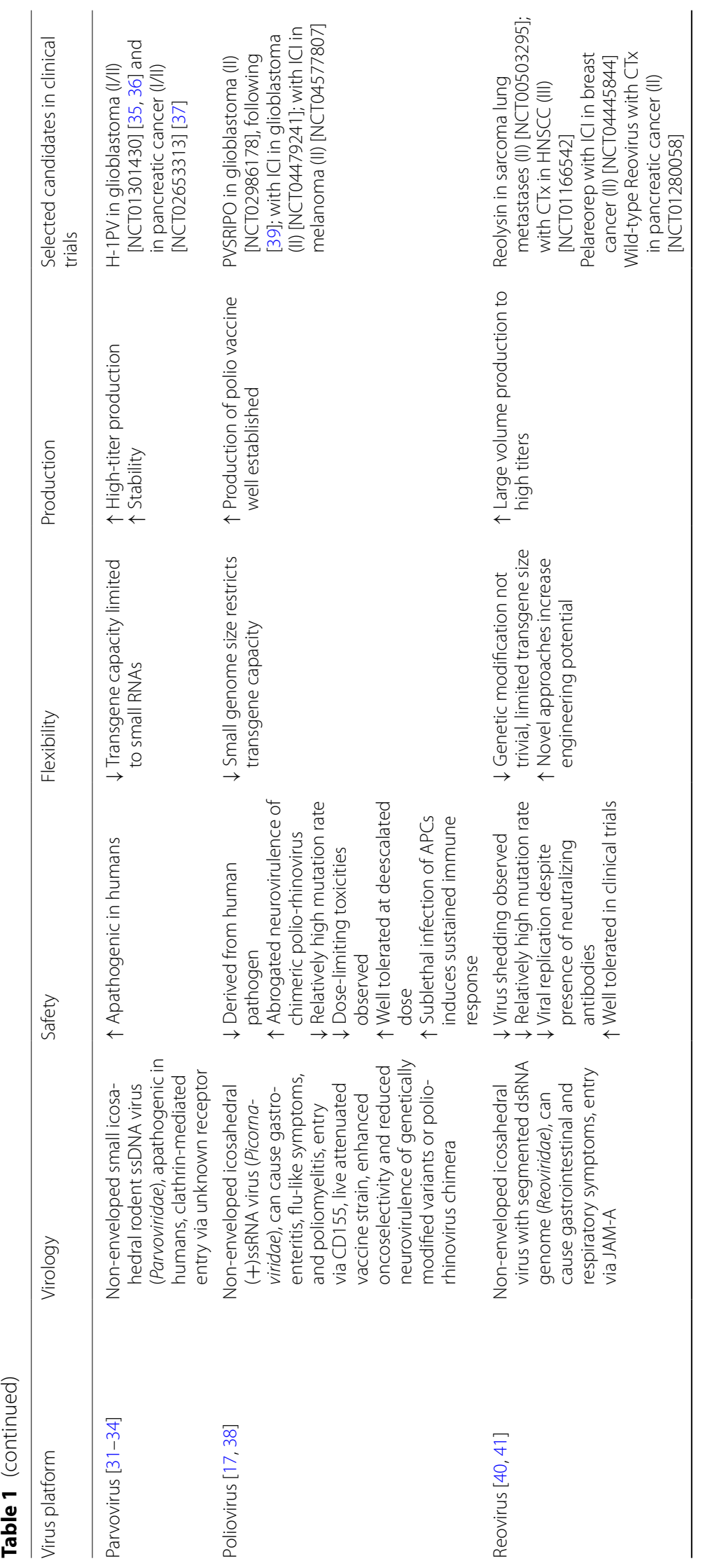




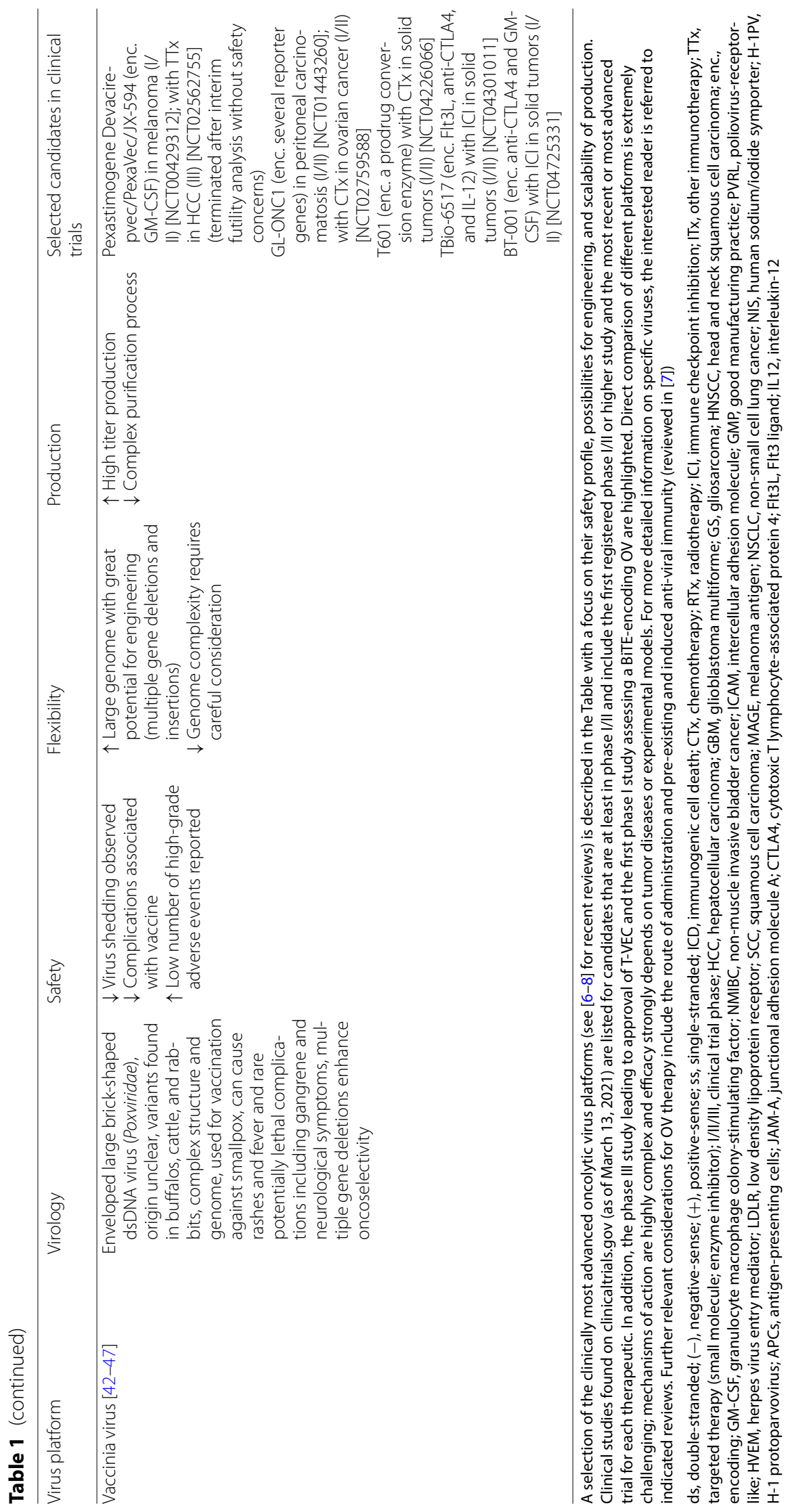




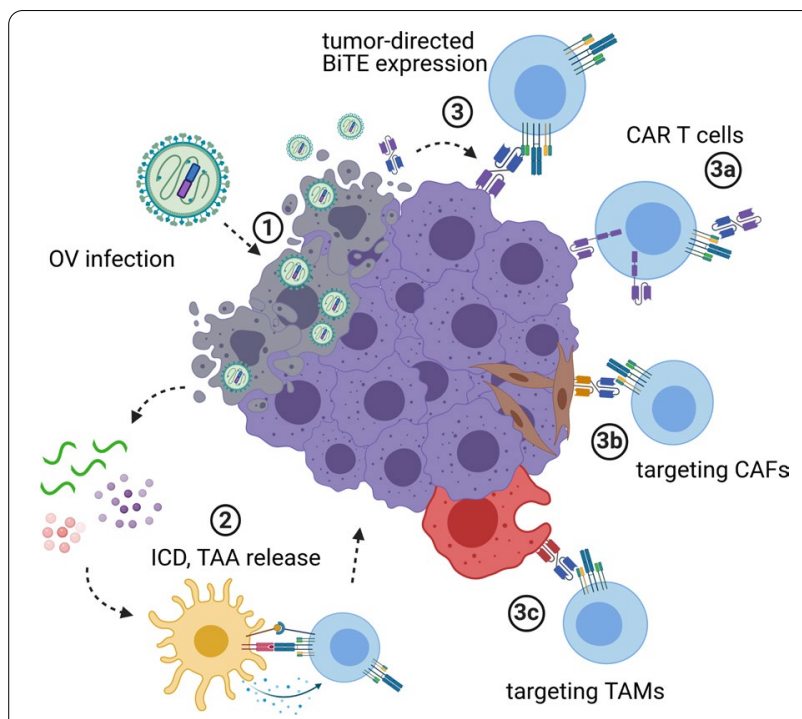

Fig. 1 BiTE-encoding oncolytic viruses for cancer immunotherapy. Oncolytic viruses (OVs) selectively infect tumor cells, followed by lytic replication (1). In addition to direct tumor debulking, viral oncolysis triggers the release of danger- and pathogen-associated molecular patterns, cytokines, chemokines, and tumor-associated antigens (2). Upon immunogenic tumor cell death (ICD), local inflammation as well as innate and adaptive anti-tumor immune responses can set the stage for effective immunotherapy. Bispecific $T$ cell engagers (BiTEs) redirect T cells to tumor cell surface antigens. OVs can be engineered for tumor-directed BiTE expression to benefit from high BiTE concentrations at the inflamed tumor site, while avoiding systemic toxicities (3). Preclinical studies have shown efficacy of this approach, utilizing BiTE-encoding OVs to engage endogenous or adoptively transferred $T$ cells, including genetically modified CART cells (3a). Aside from direct tumor cell targeting, OV-BiTEs can also be used effectively to target immunosuppressive cells of the tumor microenvironment such as cancer-associated fibroblasts (3b) and tumor-associated macrophages (3c). Created with BioRender.com

Importantly, BiTE functionality is investigated using in vitro co-culture assays with target cells and immune effector cells including appropriate controls. Although establishing the basic feasibility of encoding functional BiTEs by oncolytic viruses is not trivial, this review focuses mainly on efficacy analyses performed in ex vivo and in vivo models of cancer immunotherapy with OVBiTEs, comparing the different models and pointing out the benefits and limitations of each approach (see Table 2 for a concise summary).

\section{First studies providing proof-of-principle for the OV-BiTE concept}

In 2014, Yu et al. published the first study of a $\mathrm{T}$ cell engager-armed oncolytic virus. This study introduced an oncolytic Vaccinia virus (VV) encoding an EphA2targeted $\mathrm{T}$ cell engager (EphA2-TEA-VV) [70]. The BiTE sequence featured scFvs targeting the human CD3- $\varepsilon$ chain and an EphA2 epitope. This epitope is accessible on malignantly transformed but not on healthy epithelial cells [71]. The construct was expressed under control of a late promoter (F17R) to facilitate efficient viral replication. Yu et al. analyzed EphA2-TEA-VV using the EphA2-positive human lung cancer cell line A549 as target cells and human peripheral blood mononuclear cells (PBMCs) and PBMC-derived $\mathrm{T}$ cells, respectively, as effector cells. Virus characteristics and transgene functionality were tested in vitro. In vivo studies were performed in immunocompromised SCID/beige mice. A549 tumor cells were pre-mixed with PBMCs and injected subcutaneously (s.c.). EphA2-TEA-VV was injected intraperitoneally (i.p.) immediately thereafter. This treatment prevented tumor development completely, as opposed to treatments with PBS or control virus encoding GFP. These effects were associated with upregulation of effector cytokines. In an intravenous (i.v.) A549 lung colonization model, i.v. co-injection of PBMCs with EphA2-TEA-VV one week after tumor challenge significantly delayed tumor progression compared to control virus and monotherapies.

This study was the first to demonstrate functionality of OV-encoded BiTEs. However, the approach remained to be tested in models closer to clinical reality, where a lack of intratumoral $\mathrm{T}$ cell infiltration, an immunosuppressive microenvironment, and heterogenous target antigen expression are frequently observed [72].

Three years after this initial study, work focusing on an oncolytic adenovirus (AdV) encoding an EGFR-targeting BiTE (ICO15K-cBiTE) was published by Fajardo et al. [73]. The scFv targeting epidermal growth factor receptor (EGFR) was derived from cetuximab, a monoclonal antibody approved for treatment of metastatic colorectal cancer. The transgene was placed under control of a late promoter as in $\mathrm{Yu}$ et al., in this case the adenoviral major late promoter. In vivo efficacy of ICO15K-cBiTE was tested in immunocompromised SCID/beige mice bearing established s.c. HCT116 or A549 tumors. In the HCT116 human colorectal cancer model, pre-activated PBMCderived $\mathrm{T}$ cells were injected i.v. and IL-2 was administered i.p. to support $\mathrm{T}$ cell viability and function. In this model, intratumoral (i.t.) treatment with ICO15K-cBiTE, but not with PBS or control virus, led to accumulation of $\mathrm{T}$ cells in $50 \%$ of tumors on days four to eight post injection. Both viral and cBiTE mRNA were detected in tumor tissue following i.t. virus injection and systemic $\mathrm{T}$ cell administration. In another experiment, i.v. treatment with ICO15K-cBiTE followed by three courses of $\mathrm{T}$ cell transfer plus IL-2 i.p. resulted in delayed tumor growth compared to groups receiving parental virus or PBS. In the A549 model, the combination of i.t. ICO15K-cBiTE with two courses of unstimulated PBMCs without IL-2 support significantly delayed tumor growth compared 


\begin{abstract}
(See figure on next page.)
Fig. 2 Oncolytic virus transgene cassettes encoding bispecific T cell engagers. Generally, BiTE sequences comprise single-chain variable fragments (scFvs) targeting CD3 (blue) and either a tumor-associated antigen (TAA, purple) or cell surface antigens expressed on cancer-associated fibroblasts (yellow) or tumor-associated macrophages (red). Variable heavy $\left(V_{H}\right)$ and light $\left(V_{L}\right)$ chains of scFvs are connected by flexible, non-immunogenic glycine-serine (G/S) linkers. Most constructs harbor peptide tags for detection and/or purification purposes (green). Transgenes are preceded by regulatory domains including promoters (F17R, SA, CMV, EF1, GRP78, GRP94), a Kozak sequence for efficient translation, and leader sequences coding for secretory signaling peptides derived from immunoglobulins (all in grey). a BiTEs specific for human Ephrin type 2 receptor (EphA2) [70] and murine fibroblast activation protein (FAP) [101], respectively, are encoded by oncolytic Vaccinia viruses (VV). b ICOVIR-15-derived adenoviral vectors have been engineered to encode BiTEs targeting human epithelial growth factor receptor (EGFR) (CBiTE) $[73,74,86]$ or FAP (FBiTE, not shown) [107]. c Enadenotucirev (EnAd)-derived adenoviral vectors encode BiTEs targeting human epithelial cell adhesion molecule (EpCAM) [77], FAP (not shown) [106], or B. pertussis filamentous hemagglutinin adhesin (FHA, not shown) as a control, under control of either the constitutive cytomegalovirus (CMV) promoter or the adenoviral major late promoter via a splice acceptor (SA) site. $\mathbf{d}$ EnAd has also been engineered to express BiTEs specific for human folate receptor $\beta$ (FRB) or FHA (control, not shown), arranged in different orders with the CD3-targeting moiety being either C- or N-terminally [108]. e Four different BiTE transgene cassettes for oncolytic measles viruses (MV) have been designed, specific for either human or murine CD3 and either human carcinoembryonic antigen (CEA) or CD20 [82]. f Employing a combinatorial adenoviral vector system (CAd) with a replication-competent oncolytic adenovirus (not shown) and a helper-dependent vector, three immunomodulators have been encoded in cis; a BiTE targeting human CD44v6, a single-peptide interleukin-12 (IL-12p70), and an inhibitor of programmed death-ligand 1 (aPD-L1) [94]. TEA, T cell engager; F17R, late Vaccinia promoter; Ig, immunoglobulin; H-c, heavy chain; L-c, light chain; h, human; m, mouse; SA, splice acceptor for adenoviral major late promoter; CMV, cytomegalovirus promoter; $\mathrm{HA}$ tag, peptide from influenza A hemagglutinin; EF1, constitutive EF-1 a promoter;

GRP78/94, commercial hamster and human promoters, respectively. Created with BioRender.com
\end{abstract}

to control groups receiving parental virus or PBS or the respective monotherapies without PBMCs. Immunohistochemical analyses showed equal abundance of viral proteins in all virus-treated groups irrespective of PBMC administration, indicating virus persistence at the tumor site despite the presence of effector T cells.

Taken together, this study confirmed the functionality of BiTE-encoding OVs previously shown by $\mathrm{Yu}$ et al. using an alternative OV platform and a distinct target antigen in two xenograft models with transfer of either PBMCs or pre-activated $\mathrm{T}$ cells as effectors. Regarding the OV platform choice, the authors speculate that AdV might exhibit increased tumor cell specificity, but a reduced oncolytic rate and immunogenicity compared to VV. Compared to the previous study, the tumors had been established for a longer time before treatment and effector cells were not co-injected either with tumor cells or virus to ensure more realistic conditions. Furthermore, induction of $\mathrm{T}$ cell proliferation without exogenous IL-2 and prolonged intratumoral detection of viral transcripts and proteins, unimpaired by $\mathrm{T}$ cell activity, supported the notion of ongoing oncolysis, BiTE production, and $\mathrm{T}$ cell redirection in situ.

To increase systemic availability of ICO15K-cBiTE, Barlabé et al. utilized mesenchymal stem cells derived from menstrual blood (MenSCs) as carriers in a follow-up study [74]. The concept of AdV delivery via carrier cells was already investigated in clinical trials (NCT01844661, NCT04758533) [12]. A preclinical attempt with an oncolytic adenoviral vector not encoding an immunotherapeutic transgene had shown MenSC-mediated tumor delivery of the virus and modest anti-tumor efficacy $[75,76]$. Barlabé et al. applied this approach in NSG mice bearing s.c. A549 tumors that had received human PBMCs i.v.. In this model, only i.p. application of MenSCs infected with ICO15K-cBiTE significantly delayed tumor growth, in contrast to PBS, ICO15K alone, ICO15KcBiTE alone, and ICO15K-infected MenSCs, respectively. High intratumoral BiTE transgene expression was confirmed via RT-qPCR but correlated with reduced intratumoral adenovirus copies. The authors attributed this to competition between BiTE transgene and viral genes. $\mathrm{T}$ cell-mediated antiviral effects could provide an alternative explanation. Taken together, this study demonstrated tumor-targeted delivery of OV-BiTEs via carrier cells and anti-tumor efficacy of the strategy, however only in an immunodeficient mouse model lacking key components of the antiviral immune response such as neutralizing antibodies.

Thus, efficacy of the OV-BiTE approach still remained to be demonstrated in models with a more relevant immune contexture. This shortcoming was addressed by Freedman et al., who studied AdVs encoding an EpCAMtargeting BiTE in patient-derived ex vivo models. In this study, BiTEs were placed either under control of the constitutive CMV promoter (EnAd-CMV-EpCAMBiTE) or preceded by a splice acceptor (SA) site of the major late promoter (EnAd-SA-EpCAMBiTE), the latter restricting BiTE expression to cells supporting productive AdV infection [77]. Similar to EGFR, epithelial cell adhesion molecule (EpCAM) is frequently overexpressed on carcinomas but also present in healthy tissues, hindering systemic targeting due to toxicities (reviewed in [78]).

Importantly, the authors demonstrated $\mathrm{T}$ cell-mediated anti-tumor efficacy of the BiTE-encoding adenoviral vectors using tumor-immune cell mixtures from 


\section{a EphA2/FAP-TEA-VV}

\begin{tabular}{lllll|}
\hline F17R Ig H-chain leader & anti-humanCD3 scFv & $\mathrm{G}_{4} \mathrm{~S}$ & anti-hEphA2 \\
\hline F17R Ig H-chain leader & anti-mouseCD3 scFv & $\mathrm{G}_{4} \mathrm{~S}$ & anti-mFAP \\
\hline
\end{tabular}

\section{b IC015K-cBiTE/FBiTE}

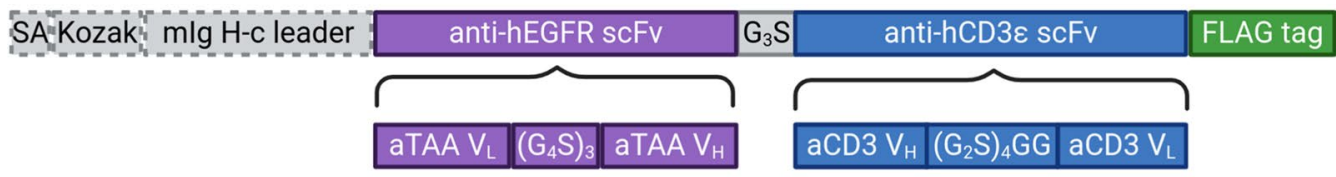

C EnAd-CMV/SA-EpCAM/FAPBiTE

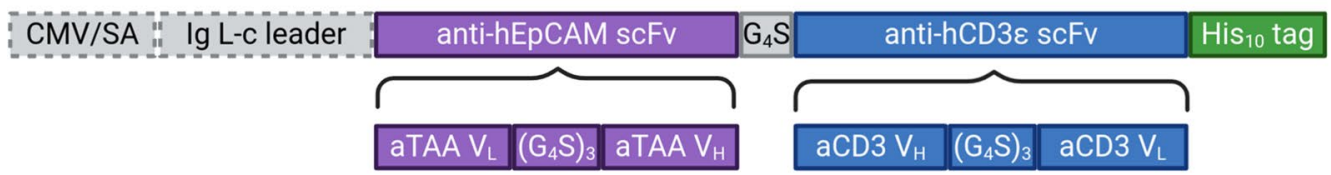

d EnAd-FR3/3FR

\begin{tabular}{|c|c|c|c|c|}
\hline CMV Ig L-c leader & anti-hFR $\beta$ scFv & $\mathrm{G}_{4} \mathrm{~S}$ & anti-hCD3\& scFv & $\mathrm{His}_{10}$ tag \\
\hline la 1 -cleade & anti-hCD3 $\varepsilon$ scFv & $\mathrm{G}_{4} \mathrm{~S}$ & anti-hFR $\beta$ scFv & $\mathrm{His}_{10}$ tag \\
\hline
\end{tabular}

e MV-BiTE

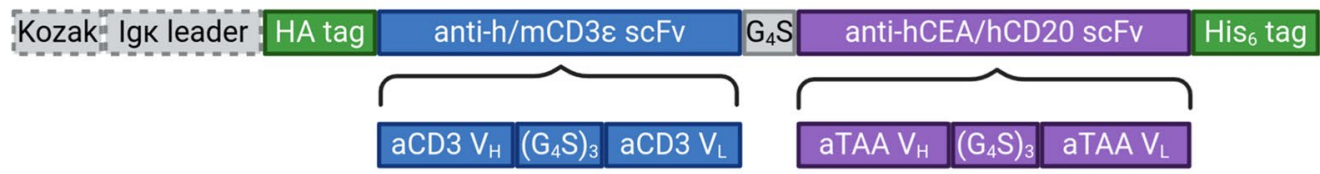

f CAd-Trio

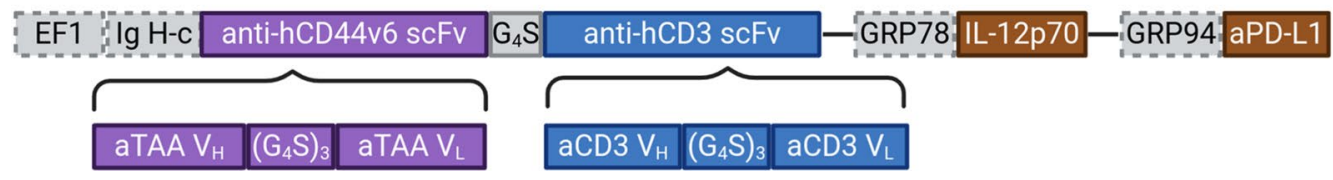

patient-derived pleural effusions and ascites fluids as described in [79]. This study was the first to show OVBiTE efficacy in primary samples comprising matched tumor cells and T cells, immunosuppressive factors such as IL-10, and an exhausted effector T cell phenotype. Results were comparable between samples from several individual patients with distinct underlying malignancies.
For EnAd-SA-EpCAMBiTE, transgene expression to was restricted to EpCAM-positive tumor cells in contrast to EnAd-CMV-EpCAMBiTE, which induced BiTE expression also in macrophages and other cells present in the malignant fluids.

This article described a second BiTE-armed AdV with a different target antigen, developed independently of 


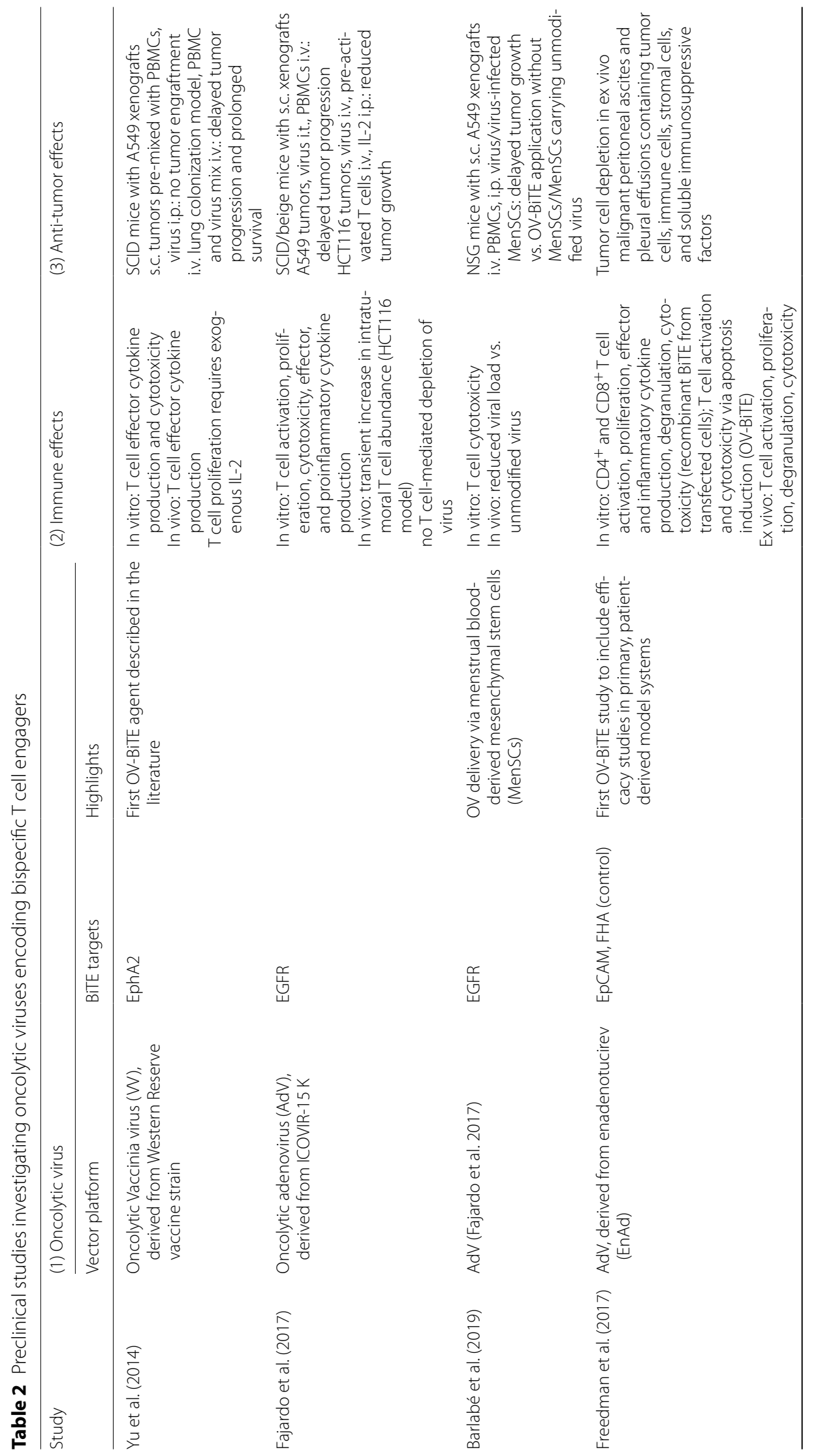




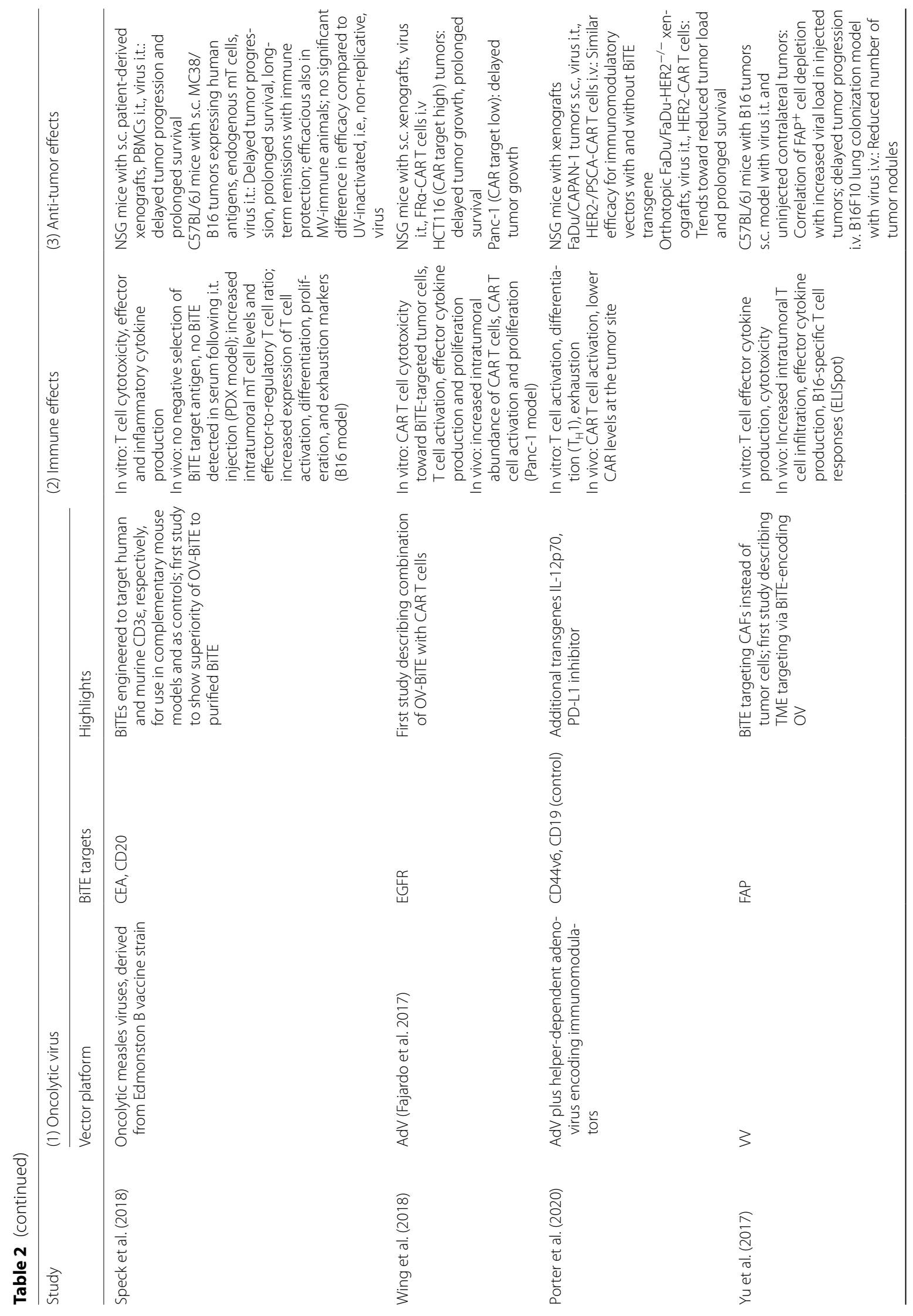




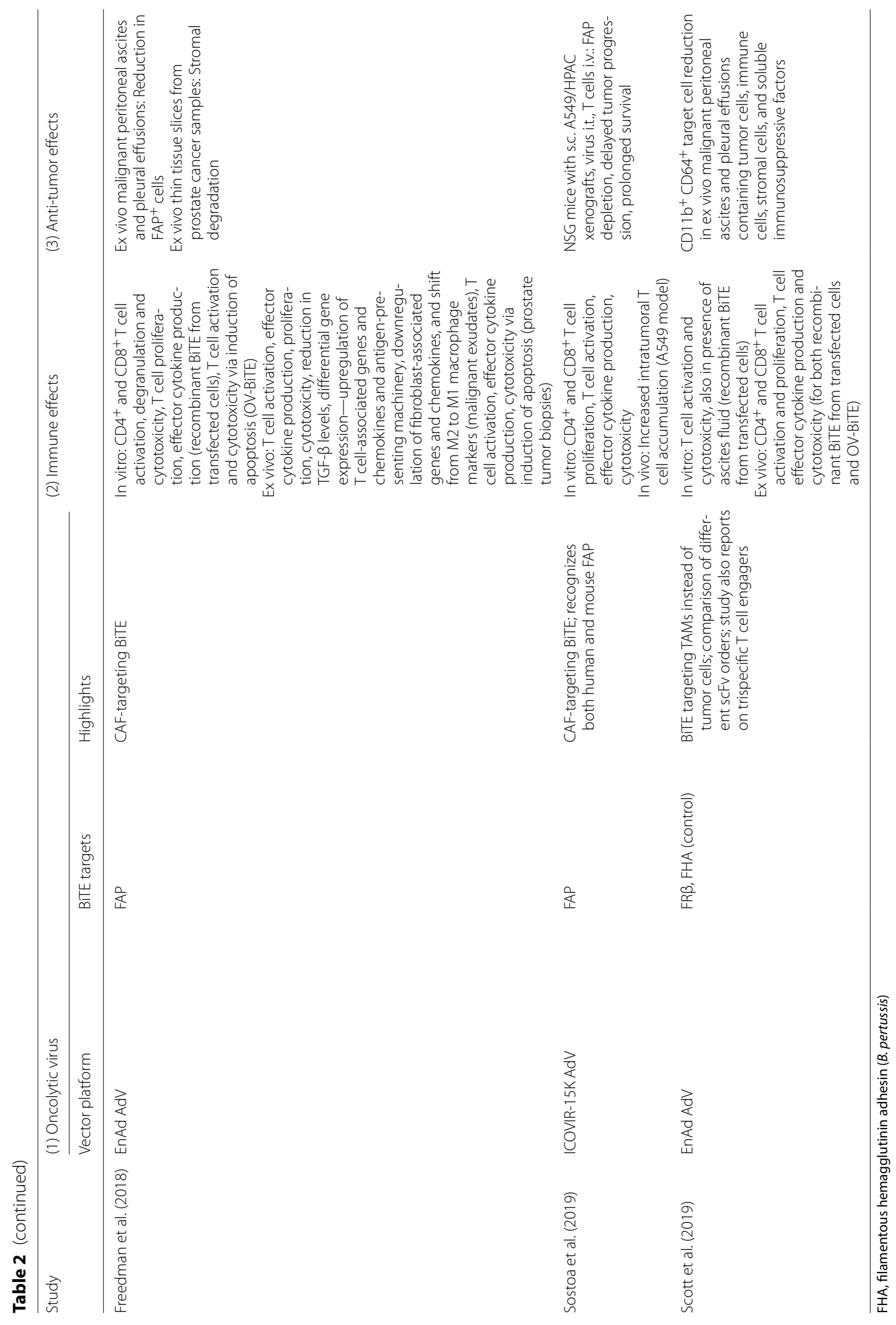


ICO15K-cBiTE. Efficacy was demonstrated in patientderived exudates as models for tumor-immune cell interactions. Successful application in these models highlights the potential of OV-directed BiTE expression under immunosuppressive conditions. In addition, the number of EpCAM-negative stromal cells present in the malignant fluids seemed to be unaffected by BiTE- or virus treatment, indicating specificity and safety of the approach. One obvious drawback of such models is the lack of three-dimensional structures and the inability to investigate the biodistribution of agents and cells. However, bloodstream stability and applicability of systemic administration of EnAd had been demonstrated in clinical trials [80, 81]. Nevertheless, the well-mixed, liquid systems applied in this study failed to show superiority of the strategy to encode the BiTE on the OV backbone. In these experimental systems, purified BiTE led to similar or sometimes superior efficacy compared to the BiTEencoding viruses, which may be attributed to higher overall BiTE concentrations. A potential benefit of OVBiTE, compared to direct application of the BiTE itself, thus remained to be demonstrated.

This was achieved in a 2018 study reporting on oncolytic measles viruses (MV) encoding BiTEs targeting the human model tumor antigens CEA and CD20, respectively [82]. The transgene cassette was inserted downstream of the measles virus hemagglutinin open reading frame to balance viral replication capacity and transgene expression. Viruses encoding BiTE variants containing scFvs targeting either human or murine CD3 were generated as described in [83] in order to investigate MV-BiTE in both patient-derived xenograft and immunocompetent mouse models.

Patient-derived xenografts were established by s.c. injection of colorectal carcinoma cultures in immunodeficient NSG mice. Mice receiving one i.t. injection of PBMCs followed by MV-CEA-BiTE i.t. on four consecutive days survived significantly longer than animals receiving either of the monotherapies. In contrast to i.v. administration, BiTE serum levels remained below the detection limit following i.t. injections of the virus. Both BiTE and viral $\mathrm{N}$ protein expression levels in tumor tissue remained stable over ten days post treatment. However, long-term survival was not observed, which was associated with a lack of $\mathrm{T}$ cell persistence, but not with MV-BiTE clearance or BiTE target antigen loss. Importantly, a fully immunocompetent mouse model was also employed. C57BL/6 mice were s.c. engrafted with tumors derived from the syngeneic murine melanoma cell line B16, expressing the human antigens CD46 and CD20 for MV entry and as a BiTE target, respectively (B16-CD20-CD46). In this model i.t. MV-CD20-BiTE treatment significantly prolonged survival compared to unmodified virus and virus encoding a non-targeting control BiTE. This correlated with increased intratumoral $\mathrm{T}$ cell infiltration and an enhanced $\mathrm{T}$ cell effector phenotype as evidenced by flow cytometry and targeted transcriptome analyses. Importantly, long-term survivors were protected from re-challenge with parental B16 cells, indicating activation of endogenous $\mathrm{T}$ cells specific for B16 melanoma antigens as opposed to human CD20 or CD46 antigens. This suggests antigen spread, potentially induced by viral oncolysis and supported by BiTE-mediated T cell redirection and recruitment. Interestingly, not only $\mathrm{T}$ cell activation, differentiation and proliferation genes were upregulated, but also genes associated with $\mathrm{T}$ cell inhibition and exhaustion. This provides a rationale for additional combinations with immune checkpoint inhibitors, which may further increase treatment efficacy. In the B16-CD20-CD46 model, several control treatment groups were analyzed, including i.t. injections of purified BiTEs, which had no significant effect on tumor growth and mouse survival on their own, and UV-inactivated viruses, which did not differ significantly in efficacy from non-inactivated counterparts. This result was consistent with observations of lowlevel measles virus replication in murine tumor cells, indicating that immunogenicity rather than direct oncolysis played the major role in this experimental model. Finally, efficacy of i.t. MV-BiTE was not impaired in MV-immunized animals, suggesting potential of the approach even in measles-seropositive individuals.

Despite the obvious limitations of both in vivo models, this study provided evidence of BiTE-encoding $\mathrm{OV}$ efficacy in both an MV-permissive tumor model in immunocompromised mice as well as in a less MV-permissive, immunocompetent model. The syngeneic B16 tumor model is known for low $\mathrm{T}$ cell infiltration, which was significantly increased by MV-BiTE treatment. For the first time, endogenous $\mathrm{T}$ cells were thus shown to be engaged for in vivo anti-tumor responses by BiTEencoding OVs. In line with the comparable efficacy of UV-inactivated virus, viral gene expression, replication, and cytotoxicity are likely limited by post-entry restriction factors in the B16 model despite ectopic CD46 expression allowing for viral entry into the tumor cells. The authors speculate that the observed results may therefore translate to even higher efficacy in the human setting with both highly virus-permissive tumors and a complete, though potentially suppressed, endogenous immune system. Correlative immuno-analysis identified $\mathrm{T}$ cell exhaustion and inhibition as an obstacle to be addressed in the future, providing a rationale for combinations with further immunotherapeutic 
approaches, in particular immune checkpoint inhibition, which had been successfully combined with MV treatment before $[84,85]$.

\section{Combination of OV-BiTE and CAR T cell therapy to address tumor heterogeneity}

While this study demonstrated efficacy of OV-BiTE via recruitment of endogenous $T$ cells, in subsequent studies the OV-BiTE approach was further combined with adoptive transfer of chimeric antigen receptor (CAR) $\mathrm{T}$ cells [86]. As an alternative to BiTEs linking the endogenous $\mathrm{T}$ cell receptor to a tumor surface antigen, patientderived $\mathrm{T}$ cells can be genetically engineered to express an artificial receptor. Such a CAR provides an extracellular antigen binding domain, a transmembrane domain, and intracellular signaling and co-stimulatory domains for efficient $\mathrm{T}$ cell redirection [87]. CAR $\mathrm{T}$ cells are activated and expanded ex vivo and reinfused into the patient for cancer therapy. In analogy to the BiTE product Blinatumomab, CD19-specific CAR T cell products have been approved for the treatment of $\mathrm{B}$ cell malignancies $[88]$ (see $[89,90]$ for a recent discussion on the benefits of both approaches). In general, CAR $T$ cell therapy provides a highly active, rapidly expanding effector cell pool but suffers from similar limitations in treating solid tumors as do BiTEs [91] and could also benefit from OVmediated immunogenic tumor cell lysis [92, 93].

Wing et al. were the first to report combination of OVBiTE with CAR T cells. By combining ICO15K-cBiTE AdV encoding an EGFR-targeting $\mathrm{T}$ cell engager with folate receptor $\alpha(\mathrm{FR}-\alpha)$-specific CAR T cells this group aimed at addressing tumor heterogeneity and potential antigen loss. Indeed, in NSG mice bearing s.c. SKOV3 (human ovarian carcinoma) tumors, the authors showed that selection of FR- $\alpha$-negative cells occurred upon CAR $\mathrm{T}$ cell monotherapy, while EGFR expression was not affected. On-target off-tumor toxicity as a safety concern of redirecting $\mathrm{T}$ cells toward tumor-associated antigens via CARs and BiTEs was also addressed in this study. Cetuximab-based EGFR-specific CARs were shown to exert increased cytotoxicity toward healthy keratinocytes and fibroblasts in vitro compared to FR-CARs. This supports the choice of FR- $\alpha$ as the CAR target and OV-mediated, tumor-directed delivery of EGFR-specific BiTEs to avoid systemic exposure.

In vivo efficacy of the combinatorial approach was investigated in two xenograft models in immunodeficient NSG mice, s.c. HCT116 (colorectal cancer) and Panc-1 (pancreatic cancer). Treatment with ICO15KcBiTE and FR-CARs significantly prolonged survival in the HCT116 model and delayed tumor progression in the Panc-1 model compared to either monotherapy alone. This correlated with enhanced intratumoral CAR T cell accumulation, proliferation, and expression of $\mathrm{T}$ cell inhibitory receptors. While both tumor cell lines express high levels of the BiTE target antigen EGFR, expression of the CAR target antigen FR- $\alpha$ differed with intermediate levels in HCT116 and low expression in Panc-1. Interestingly, treatment was efficacious in both models, indicating successful BiTE-mediated re-direction of CAR $\mathrm{T}$ cells. In addition, combination of OV-BiTE with FRCARs was more effective than combination with CD19specific CAR $T$ cells that do not target a tumor antigen in this setting. This indicates CAR-mediated killing of FR- $\alpha$ positive tumor cells in addition to BiTE-mediated killing via EGFR targeting. Taken together, this was the first study to show successful combination of OVs, BiTEs, and CARs, suggesting increased efficacy at a tolerable safety profile. Furthermore, this study introduced a strategy to address tumor heterogeneity and antigen loss by concurrent targeting of two distinct tumor surface antigens. However, the immunodeficient NSG model was not well suited to investigate potential synergistic effects including immunogenic oncolysis.

Potentially, CAR $\mathrm{T}$ cells in combination with OVBiTE could benefit from additional immunomodulators such as cytokines and immune checkpoint inhibitors. Recently, another preclinical study tested this hypothesis. Porter et al. combined CAR T cell therapy with an oncolytic helper adenovirus system encoding a BiTE, the $\mathrm{T}$ cell-stimulatory cytokine IL- 12 , and a PD-L1 inhibitor (CAd-Trio) for increased anti-tumor $\mathrm{T}$ cell activity [94]. This vector system relies on a replication-competent oncolytic adenovirus and a non-self-replicating helperdependent packaging virus encoding the immunomodulatory transgenes [95]. The authors previously reported on a variant encoding IL-12p70 and an anti-PD-L1 mini antibody only (CAd-Duo) [96, 97], which was extended here by introducing a sequence encoding a BiTE specific for CD44 variant 6 (CD44v6), a cancer-associated antigen that had been studied as an antibody- and CAR T cell-target before [98, 99].

This construct was tested in two s.c. tumor models in immunodeficient NSG mice, FaDu head and neck squamous cell carcinoma and CAPAN-1 pancreatic adenocarcinoma. CAR T cells targeting HER2 were applied in the FaDu model, and PSCA-specific CAR $\mathrm{T}$ cells were used for treatment of CAPAN-1 tumors. In these models, CAd-Trio did not show superior efficacy compared to CAd-Duo. Next, the authors tested the combinatorial approach in an orthotopic model with $\mathrm{FaDu}$ cells injected into the mouse tongue. When combined with a suboptimal number of HER2-specific CAR T cells (five times lower than in the s.c. model), CAd-Trio significantly prolonged survival compared to monotherapies. Early anti-tumor efficacy of the CAd-Trio and CAR T cell 
combination treatment was superior to CAd-Duo plus CAR $\mathrm{T}$ cells with regards to tumor reduction and $\mathrm{T}$ cell activation. However, this came at the expense of overall and long-term reduced CAR expression and increased PD-L1 levels indicating exhaustion, and the observed survival benefit did not reach statistical significance. The differences in median survival and in early anti-tumor effects between CAd-Duo and CAd-Trio were more pronounced in HER2-deficient FaDu tumors, indicating successful redirection of HER2-specific CAR T cells via the CD44v6-specific BiTE encoded by CAd-Trio. In conclusion, these data indicate efficacy of combined CAR T cell treatment, virus-mediated oncolysis, BiTE-induced $\mathrm{T}$ cell redirection and $\mathrm{T}$ cell-supporting immunomodulators in an immunodeficient mouse model. The authors now investigate the hypothesis that improved efficacy might be observed in mice harboring a humanized immune system. This study illustrates the impact of model choice on experimental outcome, highlighting the challenge of identifying suitable, i.e., clinically relevant, model systems [100].

\section{Targeting the tumor microenvironment with OV-BiTE}

Rather than targeting tumor cells directly, BiTEs can be designed to direct $\mathrm{T}$ cells against pro-tumorigenic components of the tumor microenvironment. This approach was first implemented in OV-BiTE combination therapy using a fibroblast activation protein (FAP)-specific BiTE by Yu et al. [101]. Cancer-associated fibroblasts (CAFs) exert various immunosuppressive and pro-tumorigenic functions, including secretion of transforming growth factor beta (TGF- $\beta$ ), and can be targeted via FAP (reviewed in [102, 103]). As FAP is also expressed on healthy fibroblast subsets during wound repair and tissue remodeling $[104,105]$, tumor-selective delivery by an OV may avoid toxicities. A Vaccinia-based vector encoding a murine FAP-specific BiTE (mFAP-TEA-VV) was generated analogously to EphA2-TEA-VV described in their earlier study [70]. The latter was also employed here as a control in addition to GM-CSF- and GFP-encoding VVs.

In immunocompetent C57BL/6 mice bearing s.c. B16 tumors, i.t. injections of mFAP-TEA-VV induced a significant reduction in intratumoral FAP-positive cells compared to control viruses. Interestingly, this correlated with increased viral replication, suggesting less hindrance by stromal barriers. Furthermore, mFAP-TEA-VV significantly increased intratumoral $\mathrm{T}$ cell infiltration and activation as well as systemic $\mathrm{T}$ cell responses against a B16 antigen as evidenced by ex vivo splenocyte ELISpot. Finally, albeit non-significantly, mFAP-TEA-VV delayed tumor progression compared to control viruses, also in uninjected contralateral tumors. mFAP-TEA-VV also led to a reduced number of tumor nodules upon i.v. B16 injection in a lung colonization model. In conclusion, this study provided first proof-of-concept for enhanced viral spread and anti-tumoral $\mathrm{T}$ cell responses by targeting tumor-supporting stromal cells with a virus-encoded $\mathrm{T}$ cell engager.

This strategy was also investigated using the two previously introduced oncolytic adenovirus platforms. In 2018, Freedman et al. described EnAd-derived vectors encoding a FAP-specific BiTE [106]. A vector encoding a BiTE targeting an irrelevant bacterial antigen was used as a control. As in their previous study, the authors designed vectors with BiTE expression controlled by the constitutively active CMV promoter and the major late promoter via a splice acceptor (SA) site, respectively.

In in vitro co-cultures of normal human dermal fibroblasts with $\mathrm{T}$ cells, CMV promoter-driven BiTE expression induced fibroblast killing. For the SA vector, $\mathrm{T}$ cell-mediated lysis of FAP-positive cells, also in healthy donor-derived bone marrow samples, required presence of AdV-permissive tumor cells, indicating tumor cellrestricted virus replication and BiTE secretion and thus enhanced safety. Malignant peritoneal ascites samples comprising cancer cells, tumor-associated macrophages (TAMs), CAFs, T cells-a majority of which displayed an exhausted phenotype-and soluble immunosuppressive factors were used as an ex vivo model system to investigate efficacy of EnAd-FAP-BiTE. Cell-free ascites fluid inhibited activation of $\mathrm{T}$ cells by anti-CD3/CD28 beads, but not by FAP-BiTEs. Accordingly, in contrast to control vectors, EnAd-FAP-BiTE induced $\mathrm{T}$ cell activation and cytotoxicity, leading to depletion of FAP-positive cells and subsequent drops in TGF- $\beta$ levels, in several patient-derived ascites cultures. These effects were not observed in a patient sample lacking tumor cells, supporting the notion of increased safety by explicit tumor restriction of this vector. Interestingly, not only $\mathrm{T}$ cellrelated chemokines and effector molecules, but also genes involved in DC maturation and antigen presentation were upregulated upon treatment with EnAd-SAFAP-BiTE compared to controls in several biopsies. This indicates potential for antigen spread and activation of endogenous, polyclonal $\mathrm{T}$ cells to support lasting anti-tumor responses. In addition, EnAd-SA-FAP-BiTE induced repolarization of TAMs from a pro-tumorigenic "M2" toward a more pro-inflammatory "M1" phenotype. Activity of EnAd-SA-FAP-BiTE was furthermore demonstrated on thin tissue slices derived from prostate cancer biopsies. Following virus inoculation in cultivation media, viral infection and BiTE expression were detected in malignant tissue containing EpCAM-positive tumor cells and FAP-expressing CAFs via immunohistochemistry (IHC) and fluorescence microscopy. In contrast to 
a virus encoding a control BiTE, infection with EnAdSA-FAP-BiTE resulted in $\mathrm{T}$ cell activation and ELISA revealed effector cytokine production. Induction of apoptosis and stromal degradation was restricted to FAPpositive samples as evidenced by IHC, caspase cleavage, and LDH release assays, indicating BiTE-mediated cytotoxicity.

As in their previous publication describing EpCAMBiTE-encoding vectors, the authors showed efficacy of CAF targeting by EnAd-FAP-BiTE in complementary patient-derived samples ex vivo. This study prompted a clinical trial with an oncolytic adenovirus encoding a FAP-TAc ( $\mathrm{T}$ cell activator) as well as IFN- $\alpha$, CXCL9, and CXCL10 to further support $\mathrm{T}$ cell activation (PsiOxus T-SIGn platform, NG-641, NCT04053283). The phase Ia/b study will first investigate i.t. or i.v. dose escalations in several epithelial cancer entities and then assess safety and efficacy of the monotherapy compared to combinations with checkpoint inhibition and/or chemotherapy.

CAF-targeting by OV-BiTE was also investigated using the ICOVIR oncolytic adenovirus platform. To this end, ICO15K-FBiTE encoding a FAP-specific BiTE under control of the adenoviral major late promoter was generated, harboring an N-terminal signal peptide and a FLAG-tag at the C-terminus [107]. The two papers by Freedman et al. [106] and de Sostoa et al. [107] describe very similar approaches and constructs and were published only two months apart. In contrast to the EnAd-FAP-BiTE study, de Sostoa et al. employed immunodeficient mouse models instead of clinical samples for efficacy testing.

The mouse models in this study included NSG mice bearing s.c. A549 or HPAC (human pancreatic adenocarcinoma) tumors with i.v. adoptive transfer of human $\mathrm{T}$ cells. In both models, i.t. ICO15K-FBiTE treatment delayed tumor growth and significantly prolonged survival compared to control virus or PBS. In the A549 model, this was also associated with higher intratumoral T cell infiltration. High FBiTE expression was detected in ICO15K-FBiTE-treated tumors via RT-qPCR and correlated with significantly decreased mFAP levels compared to PBS-treated tumors in both models. In combination with $\mathrm{T}$ cell administration, control virus also prolonged survival and reduced mFAP levels compared to PBS in the A549, but not the HPAC model, suggesting BiTEindependent virus $-\mathrm{T}$ cell interactions. Taken together, these findings indicate virus-induced tumor cell lysis and BiTE-dependent, $\mathrm{T}$ cell-mediated depletion of mFAPpositive murine stromal cells in vivo upon $\mathrm{T}$ cell transfer, resulting in delayed tumor progression and prolonged survival. Efficacy of the OV-FAP-BiTE approach was thus demonstrated in immunocompetent mice [101], in clinical biopsies ex vivo [106], and in immunodeficient mouse models of human tumors [107].
In a recent study, Scott et al. explored OV-encoded $\mathrm{T}$ cell-engagers to target another immunosuppressive cell type of the tumor microenvironment, tumor-associated macrophages [108]. As described above, Freedman et al. had previously reported repolarization of M2-like macrophages toward a favorable M1 phenotype by targeting CAFs via EnAd-SA-FAP-BiTE [106]. Here, the authors aimed at TAM depletion via BiTEs targeting the antigens CD206 and folate receptor $\beta$ (FR- $\beta$ ), respectively. Upregulation of these markers was confirmed on macrophages in the majority of cancer patient-derived ascites samples as well as on healthy monocyte-derived macrophages cultured with ascites fluid.

The authors found that trispecific engagers (TriTEs), harboring an additional CD3 scFv linked to the CD206 BiTE $\mathrm{N}$-terminus, showed increased $\mathrm{T}$ cell activation and macrophage killing in co-cultures, also in presence of immunosuppressive ascites fluid. Using malignant ascites-derived cell mixtures, however, both CD206-targeting and non-targeting control TriTE induced similar reduction of $\mathrm{CD} 11 \mathrm{~b}+\mathrm{CD} 64+$ cells, indicating unspecific toxicity. Interestingly, a different approach to modifying the FR- $\beta$ BiTE by reversing the scFv order to $\mathrm{N}$-terminal CD3 and C-terminal FR- $\beta$ targeting increased efficacy of this BiTE in ascites cell mixtures. This variant, termed 3FR as opposed to the original FR3 BiTE, was identified as the most effective also in the context of EnAd-CMVFR- $\beta$ vectors. The 3FR BiTE-encoding virus induced stronger $\mathrm{T}$ cell activation and CD11b + CD64+ cell killing in whole ascites samples than empty EnAd, EnAdCMV-FR3, and viruses encoding control BiTEs. Taken together, Scott et al. demonstrated feasibility of TAM targeting by BiTE-encoding oncolytic adenoviruses in patient-derived malignant ascites models. They devised the addition of further scFvs to generate TriTEs and the optimization of $\mathrm{scFv}$ order as two strategies to improve engager molecule function. In addition, a nanobody instead of an scFv was used to target CD206. Nanobodies are derived from heavy chain only antibodies found in camelids [109] and sharks [110] (reviewed in [111]). These findings indicate vast potential of both vector and engager molecule engineering for safer and more efficient cancer immunotherapy, requiring further mechanistic exploration of the OV-BiTE approach.

\section{Discussion}

\section{OV-BiTE: concept and design}

The preclinical studies discussed in this article demonstrate that oncolytic viruses are ideal vehicles for tumorrestricted delivery of BiTEs as immunomodulatory transgenes. In general, transgene design was quite similar across these studies, comprising N-terminal immunoglobulin-derived secretory signal sequences and mostly 
C-terminal tags for detection purposes. The scFvs were connected via flexible, non-immunogenic glycine-serine linkers. Viral replication kinetics and virus-mediated tumor cell lysis as well as BiTE secretion, binding specificity, and functionality were demonstrated in vitro using appropriate assays. OV-BiTE treatment efficacy in terms of enhanced $\mathrm{T}$ cell activation, effector phenotype induction, proliferation, intratumoral infiltration, cytokine production, and cytotoxicity, was demonstrated in complementary tumor models in vitro, in vivo, and ex vivo. These proof-of-concept studies provide strong preclinical evidence for feasibility of the approach for various model target antigens and across distinct vector platforms.

Different classes of potential target antigens exist for cancer therapy. These include (upregulated) tumorassociated antigens like the BiTE and CAR target CD19 that are also found on healthy tissues [1, 112, 113], developmental or cancer-testis antigens whose expression is restricted to certain developmental stages or immune-excluded tissues [114, 115], as well as antigens accessible exclusively on tumor cells, including mutated neoantigens [116] and "liberated" antigens normally present in a bound, closed conformation. The first published OV-BiTE study used such an antigen, EphA2 [70]. Other studies used tumor-associated antigens such as EGFR [73, 74, 86] and EpCAM [77] that are present on vital healthy tissues, leading to toxicities if targeted systemically. Study data show feasibility of OV-mediated, tumor-directed BiTE expression, potentially enabling targeting of such antigens at reduced on-target, off-tumor toxicity. However, safety studies explicitly addressing this promise of OV-BiTE therapy are currently lacking. In contrast to many immunotherapy approaches $[117,118]$, OV-BiTE directly targets tumor surface antigens and can thus address cancers with immune-evasive defects of the antigen presentation machinery [119]. Of note, OV-BiTE treatment did not induce downregulation of the BiTE target antigen in a mouse model [82].

\section{Diverse OV platforms in clinical development}

Oncolytic vectors from different virus families are currently being tested in clinical studies (see Table 1 for a concise comparison). The majority of all OV-BiTE publications (eight of eleven) investigated adenovirus-based oncolytics, reflecting the current status of clinical virotherapy trials [7]. Adenoviruses are icosahedral DNA viruses which are well-studied, also as non-replicating vectors for gene therapy. Safety concerns have been addressed by genetic modifications restricting virus replication, e.g., to tumor cells with p53 and/or pRb mutations (reviewed in [120]). Adenovirus characteristics and structural properties enable high-titer production and efficient purification. Besides Enadenotucirev
(EnAd) (NCT02636036, NCT02028117, NCT02028442, NCT03916510, NCT02053220), which was further engineered to generate the EnAd-EpCAM-BiTE and EnAd-FAP-BiTE vectors described in this review, DNX2401 is among the clinically most advanced adenovirus-based oncolytics (NCT03896568, NCT03178032, NCT02798406, NCT01956734, NCT02197169, NCT00805376)]. In addition, DNX-2440 is investigated in a Phase I trial (NCT03714334).

Vaccinia vectors were used in two OV-BiTE studies. Vaccinia viruses are DNA viruses derived from the live smallpox vaccine. VV oncolytic properties, safety, and large transgene capacity have been demonstrated in a number of preclinical and clinical studies (reviewed in [121]). JX-594 or PexaVec, a VV encoding GM-CSF, had advanced to a phase III clinical trial for the treatment of hepatocellular carcinoma (NCT02562755), for which enrolment was stopped prematurely without safety concerns following an interim futility analysis [122]. Further studies investigating treatment with different oncolytic Vaccinia viruses, e.g., GL-ONC1 (NCT02759588, NCT01766739) and T601 (NCT04226066), and PexaVec in combination with immune checkpoint inhibitors (NCT03206073, NCT02977156), highlight the potential of this particular oncolytic virus platform for clinical translation.

Oncolytic measles viruses are derived from live attenuated vaccine strains developed against infection with wild-type measles virus, a single-stranded negative sense RNA virus of the Paramyxoviridae family known to cause the potentially severe measles disease [123]. Safety and tolerability of these vaccine strains and oncolytic MV have been extensively documented in numerous studies [28]. Oncolytic measles vectors are furthermore characterized by high immunogenicity, natural oncotropism, and flexibility in terms of genetic modification (reviewed in $[26,27,29,123,124])$. One bottleneck in the development of oncolytic measles viruses is large-scale production and purification of infectious progeny [125, 126]. The most advanced vectors in clinical trials encode CEA as a soluble biomarker for viral gene expression and human sodium/iodide symporter (NIS), respectively, for imaging and radiotherapy (reviewed in [28]). Remarkably, a durable complete remission was observed in a multiple myeloma patient receiving a single high dose of MV-NIS i.v. $[30,127]$.

A recent study used a fourth $\mathrm{OV}$, reovirus, for preconditioning prior to BiTE treatment rather than directly using BiTE-encoding vectors [128]. In this paper, reovirus treatment of immunocompetent mice bearing s.c. KPC3 murine pancreatic tumors was shown to induce an interferon response in tumor tissue, followed by an influx of immune effector cells. This resulted in an immune 
microenvironment conducive to BiTE therapy. In line with these findings, the authors identified sequential treatment with reovirus and BiTE as the most effective treatment order in complementary murine tumor models. However, this approach lacks one of the main advantages of the OV-BiTE strategy, local BiTE expression at the site of viral infection to reduce systemic BiTE-mediated side effects outside of the tumor. Nevertheless, the study illustrates that the precise mechanisms of action and kinetics of immunovirotherapy remain to be fully understood and need to be harnessed for optimal therapeutic efficacy.

As outlined above, the OV-BiTE approach has been successfully implemented with several distinct $\mathrm{OV}$ vector platforms, all of which have potential for clinical application. To enable a rational choice of optimal vectors for particular treatment indications and patient subpopulations, systematic comparisons will be required in the future and efforts toward this end have been initiated $[129,130]$. However, a major challenge is to identify appropriate models allowing for direct comparison of distinct OVs. Thus, various vector platforms are being developed for cancer immunotherapy, each of which will likely have benefits for particular applications.

One impediment to OV therapy is premature viral clearance, either by hepatic uptake or virus-neutralizing antibodies, depending on the specific OV (reviewed in [131]). One means to circumvent these limitations are carrier cells. This has also been demonstrated for BiTEencoding OVs by Barlabé et al. [74]. Virus specificity and tumor targeting can be enhanced by further virus modifications, including re-targeting of viral attachment proteins and polymer coating to prevent antibody neutralization (reviewed in [132]).

Moreover, additional possibilities of virus engineering, especially encoding additional transgenes, open a plethora of opportunities to further improve efficacy. Previously described immunomodulatory transgenes encoded by oncolytic vectors include cytokines [21, 133] and immune checkpoint inhibitors [84, 134]. A recent study demonstrated successful combination of several immunomodulators on the same oncolytic adenovirus vector system: In xenograft models with CAR $\mathrm{T}$ cell transfer, treatment with viruses encoding a cytokine and a checkpoint inhibitor in addition to a BiTE was superior to viruses lacking the BiTE transgene or encoding the BiTE alone [94].

\section{Source, specificity and functionality of $\mathrm{T}$ cells}

Aside from diverse OV vectors, different sources of $\mathrm{T}$ cells have been employed in OV-BiTE studies. Efficacy has been demonstrated with endogenous and adoptively transferred, unmodified and genetically engineered $\mathrm{T}$ cells in the existing literature. Importantly, endogenous $\mathrm{T}$ cells in immunocompetent mouse models and in primary ex vivo samples, having experienced immunosuppressive microenvironments, were shown to be successfully engaged via OV-BiTEs [77, 82, 101, 106, 107]. Despite limitations with regards to displaying more complex immune interactions, adoptive transfer in immunodeficient mouse models allowed for assessment of OV-BiTE efficacy in presence and absence of $\mathrm{T}$ cells. Furthermore, genetically engineered $\mathrm{T}$ cells can be applied, as shown for combinations of OV-BiTEs with CAR T cells addressing tumor antigen heterogeneity [86, 94]. Ectopic expression of conventional [135] or engineered $\mathrm{T}$ cell receptors [136] add to the repertoire of $\mathrm{T}$ cell re-direction approaches. One recent strategy utilizes engineered T cells to express BiTEs [137, 138], aiming at redirecting $\mathrm{T}$ cells in situ. However, as opposed to OV delivery, this may not necessarily overcome current limitations of BiTE therapy regarding intratumoral infiltration of $\mathrm{T}$ cells and on-target off-tumor toxicities. In addition, tumor-infiltrating virus-specific $\mathrm{T}$ cells induced by OV therapy can represent a potent effector cell pool for BiTE-mediated tumor cell killing [128]. An alternative approach makes use of a truncated CD19 antigen encoded by an oncolytic Vaccinia virus, aiming at directing CD19-specific CAR T cells toward virus-infected cells [139]. Interestingly, enhanced viral spread was observed upon CAR T cell killing of infected cells. While the study convincingly demonstrates successful preclinical implementation, OV-encoded cell surface antigens lack the advantage of bystander killing of uninfected cells provided by encoding secreted BiTEs.

Irrespective of $\mathrm{T}$ cell source and specificity, $\mathrm{T}$ cell functionality is decisive for OV-BiTE efficacy. This can be limited by immune checkpoints. Accordingly, different OV platforms have been combined successfully with checkpoint inhibition in preclinical $[61,62,84,85,140]$ and clinical [60] studies, including the aforementioned BiTEencoding AdV [94]. However, this is not the only potentially detrimental mechanism of immunosuppresion.

\section{The complexity of the tumor microenvironment}

The multi-faceted interactions between OV-BiTE therapy and $\mathrm{T}$ cells are complicated further by the tumor microenvironment (TME). While containing stromal barriers and immunosuppressive factors limiting treatment efficacy, the TME can be deployed to improve therapeutic outcome. For example, not only $\mathrm{T}$ cells and OVs, but also macrophages can be genetically modified to secrete BiTEs. In a s.c. glioblastoma xenograft model with i.v. T cell injection in NSG mice, i.t. administration of engineered macrophages secreting EGFRvIII-BiTEs resulted in enhanced $\mathrm{T}$ cell responses and delayed tumor 
progression [141]. When combined with IL-12-secreting macrophages in addition, tumor growth was completely abrogated in this model, indicating the potential of TME modulation. Accordingly, OV-BiTEs targeting components of the tumor microenvironment, namely tumor-associated macrophages and cancer-associated fibroblasts (CAFs), were shown to be successful in several preclinical studies [101, 106, 107]. Recently, an oncolytic adenovirus has been shown to simultaneously target both glioblastoma cells and CAF-like pericytes in a murine brain tumor model [142]. Further approaches harnessing the interplay between virotherapy and the tumor microenvironment have been reviewed elsewhere [103, 143]. These include addressing the tumor vasculature $[53,144]$, myeloid-derived suppressor cells [145-147], and tumor cell subsets like tumor-initiating [148] or cancer stem cells [149].

The intricate interplay of combinations using advanced oncolytic vectors, $\mathrm{T}$ cells, and TME targeting therapeutics results in an infinite complexity, which does not allow systematic testing of all possible combinations. This may be addressed by in silico approaches using experimental data to simulate outcome of hypothetical treatments to prioritize the most promising strategies (reviewed in [150-153]).

\section{Considerations for clinical translation}

Major challenges in taking the OV-BiTE approach forward toward clinical translation are the choice of appropriate BiTE targets, of best-suited OV platforms for particular indications, and, importantly, of appropriate models that optimally reflect the human setting in terms of pharmacology and predicting side effects. The preclinical studies presented in this review have demonstrated proof-of-concept in complementary tumor models including ex vivo samples from human patients and more artificial mouse models that provide three-dimensional organ orientation and interconnection but have limitations regarding virus susceptibility and/or adequate immune responses. In addition, GMP-compatible upscaling of OV-BiTE vector production for clinical testing is not trivial (reviewed in [154]). Generation of viruses in a laboratory for preclinical research differs fundamentally from development and manufacturing of a novel medical product. Regulatory guidelines are complex and need to be addressed from an early development stage on to ensure safe and successful clinical translation (reviewed in [155]). Producer cell and virus seed batches, cultivating and harvesting procedures, downstream purification and identity validation have to be pre-defined and constantly controlled for quality. Although oncolytic vector platforms differ in their respective production processes, standardized protocols enable GMP-compatible manufacturing. For some viruses, e.g., vesicular stomatitis virus, high-titer production of purified progeny can be relatively fast and straightforward [156]. Others, such as measles virus-derived oncolytics, are harder to produce at high titers and purification is aggravated by a pleomorphic structure and sensitivity to $\mathrm{pH}$ changes and shear stress [125, 126, 157]. Combinations with advanced immunotherapeutics such as CAR T cells require further consideration in terms of target, design, scalability, safety, and the regulatory framework (reviewed in [158]).

Although these considerations prevent rapid translation of most approaches, the first clinical OV-BiTE trial has already been initiated: NG-641, an EnAd-derived vector armed with a FAP-specific BiTE (FAP-TAc antibody) and an additional immune-stimulatory molecule (CXCL9-CXCL10-IFNa), is being investigated both as i.v. and i.t. treatment across different epithelial tumor entities (NCT04053283). Study completion is expected for the end of 2022. The results are eagerly awaited and may provide further insights into safety/tolerability and efficacy of immunotherapy with BiTE-encoding oncolytic viruses and potentially beneficial combination regimens.

The OV-BiTE approach is one of several immunovirotherapeutic strategies now entering clinical investigation. GM-CSF encoding derivatives of several OV platforms have been studied in numerous clinical trials (reviewed in [56]). These include the clinically most advanced oncolytic therapeutics: T-VEC, derived from a herpes simplex virus type I and approved for treatment of malignant melanoma following a successful study [21], and vaccinia-based PexaVec, which had progressed to a phase III trial in hepatocellular carcinoma (NCT02562755). In addition, OVs encoding a range of novel transgenes are now in Phase I/II studies. These include cytokines and $\mathrm{T}$ cell costimulatory molecules, with candidates such as TILT-123, an oncolytic adenovirus encoding TNF- $\alpha$ and IL-2 (NCT04217473) and delolimogene mupadenorepvec/LOAd703 encoding membrane-bound CD40L and 4-1BBL (NCT04123470, NCT02705196, NCT03225989). As in LOAd703, combinations of two or multiple immunomodulators are not uncommon. Examples include RIVAL 01/TBio-6517, a Vaccinia virus for tumor-directed expression of FLT3L, anti-CTLA-4, and IL-12 (NCT04301011), and ONCR-177 (NCT04348916), an HSV-1 mediating expression of IL-12, FLT3LG, CCL4, anti-PD-1, and anti-CTLA-4 to enhance induction of tumor-specific adaptive immunity. Another variation of the oncolytic vaccination paradigm is to encode tumor antigens within the viral vector as a heterologous cancer vaccine. Studies with MG-1 Maraba viruses encoding HPV E6/E7 and MAGEA3, respectively, are ongoing (NCT03618953, NCT03773744, NCT02879760). In the majority of trials, these viral vectors are combined with 
systemic PD-1 immune checkpoint blockade. The design of these trials illustrates the significant advancement and increasing complexity of the field. These developments underline the necessity of both preclinical and translational research as drivers of progress in modern medical oncology. Complementary research even in early-stage clinical development can provide first-hand insight to decipher which approaches will bring most benefit for cancer patients. Identifying correlates of response and resistance will aid in prioritizing and refining treatment strategies in immunovirotherapy.

\section{Conclusions}

In this regard, the OV-BiTE approach is one example. Starting from a clear scientific rationale, several independent preclinical studies have provided proof-ofconcept for this strategy. Thus, OV-BiTEs must now demonstrate applicability and efficacy in clinical reality. Variations of vector platform and target molecules as well as combination therapies offer a plethora of opportunities for improvement. Therefore, early clinical investigations should also address mechanistic aspects to provide avenues for further development.

\begin{abstract}
Abbreviations
AdV: Oncolytic adenovirus; APCs: Antigen-presenting cells; BiTEs: Bispecific T cell engagers; CAd: Combinatorial adenoviral vector system; CAFs: Cancerassociated fibroblasts; CAR: Chimeric antigen receptor; CD44v6: CD44 variant 6; CEA: Carcinoembryonic antigen; CMV: Cytomegalovirus; CTLA-4: Cytotoxic T lymphocyte-associated protein $4{ }_{i i} C T x$ : Chemotherapy; DAMPs and PAMPs: Danger- and pathogen-associated molecular patterns; ds: Double-stranded; EGFR: Epidermal growth factor receptor; EnAd: Enadenotucirev; enc.: Encoding; EpCAM: Epithelial cell adhesion molecule; EphA2: Ephrin type 2 receptor; FAP: Fibroblast activation protein; FHA: B. pertussis Filamentous hemagglutinin adhesin; Flt3L: Flt3 ligand; FR- $\alpha$ : Folate receptor a; FR- $\beta$ : Folate receptor $\beta$; GBM: Glioblastoma multiforme; GM-CSF: Granulocyte macrophage colonystimulating factor; GMP: Good manufacturing practice; GS: Gliosarcoma; H-1PV: H-1 protoparvovirus; HCC: Hepatocellular carcinoma; HNSCC: Head and neck squamous cell carcinoma; HVEM: Herpes virus entry mediator; i.p.: Intraperitoneally; i.t.: Intratumoral; i.v.: Intravenous; ICAM: Intercellular adhesion molecule; ICD: Immunogenic tumor cell death; ICI: Immune checkpoint inhibition; IHC: Immunohistochemistry; IL-12: Interleukin-12; ITx: Immunotherapy; JAM-A: Junctional adhesion molecule A; LDLR: Low-density lipoprotein receptor; MAGE: Melanoma antigen; MenSCs: Mesenchymal stem cells derived from menstrual blood; MV: Measles virus; NIS: Sodium/iodide symporter; NMIBC: Non-muscle invasive bladder cancer; NSCLC: Non-small cell lung cancer; OV-BiTE: BiTE-encoding oncolytic virus; OVs: Oncolytic viruses; PBMCs: Peripheral blood mononuclear cells; PD-L1: Programmed death-ligand 1; PVRL: Poliovirus-receptor-like; RTx: Radiotherapy; s.c.: Subcutaneously; SA: Splice acceptor; SCC: Squamous cell carcinoma; scFv: Single-chain variable fragments; ss: Single-stranded; TAA: Tumor-associated antigen; TAc: T cell activator; TAMs: Tumor-associated macrophages; TGF- $\beta$ : Transforming growth factor beta; TME:Tumor microenvironment; TriTEs: Trispecific engagers; TTx: Targeted therapy; $\mathrm{T}-\mathrm{VEC}$ : Talimogene laherparepvec; $\mathrm{V}_{H} \mathrm{~V}_{L}$ : Antibody variable heavy and light chains; $\mathrm{V}$ : Vaccinia virus.
\end{abstract}

\section{Acknowledgements}

We thank Gemma Pidelaserra Martífor critical reading of the manuscript. We acknowledge all members and affiliates of the Clinical Cooperation Unit Virotherapy for productive discussions and their continuous support.

\section{Authors' contributions}

Conception, writing, and editing of the manuscript: JPWH and CEE. Both authors read and approved the final manuscript.

\section{Funding}

This work was supported by the German National Science Foundation (DFG, Grant EN-1119/2-2 to CEE) and the Wilhelm Sander Foundation (Grant 2018.058.01 to CEE). JPWH receives an NCT Heidelberg School of Oncology $\left(\mathrm{HSO}^{2}\right)$ Fellowship.

\section{Availability of data and materials \\ Not applicable.}

\section{Declarations}

Ethics approval and consent to participate

Not applicable.

\section{Consent for publication}

Not applicable.

\section{Competing interests}

CEE is listed as inventor on patents describing immunomodulatory oncolytic viruses. JPWH declares that he has no competing interests.

\section{Author details}

${ }^{1}$ Research Group Mechanisms of Oncolytic Immunotherapy, Clinical Cooperation Unit Virotherapy, German Cancer Research Center (DKFZ), National Center for Tumor Diseases (NCT), University Hospital Heidelberg, Heidelberg, Germany. ${ }^{2}$ Department of Medical Oncology, University Hospital Heidelberg, Heidelberg, Germany. ${ }^{3}$ Center for Biomedical Research and Education (ZBAF), School of Medicine, Institute of Virology and Microbiology, Faculty of Health, Witten/Herdecke University, Witten, Germany.

Received: 6 December 2020 Accepted: 30 March 2021

Published online: 16 April 2021

\section{References}

1. Yu J, Wang W, Huang H. Efficacy and safety of bispecific T-cell engager (BiTE) antibody blinatumomab for the treatment of relapsed/refractory acute lymphoblastic leukemia and non-Hodgkin's lymphoma: a systemic review and meta-analysis. Hematology (Amsterdam, Netherlands). 2019;24(1):199-207.

2. Yu S, Li A, Liu Q, Yuan X, Xu H, Jiao D, Pestell RG, Han X, Wu K. Recent advances of bispecific antibodies in solid tumors. J Hematol Oncol. 2017;10(1):155.

3. Goebeler ME, Bargou RC. T cell-engaging therapies-BiTEs and beyond. Nat Rev Clin Oncol. 2020;17(7):418-34.

4. Esfahani K, Roudaia L, Buhlaiga N, Del Rincon SV, Papneja N, Miller WH Jr. A review of cancer immunotherapy: from the past, to the present, to the future. Curr Oncol. 2020;27(Suppl 2):S87-s97.

5. Waldman AD, Fritz JM, Lenardo MJ. A guide to cancer immunotherapy: from T cell basic science to clinical practice. Nat Rev Immunol. 2020;20(11):651-68.

6. Cook M, Chauhan A. Clinical application of oncolytic viruses: a systematic review. Int J Mol Sci. 2020;21(20):7505.

7. Macedo N, Miller DM, Haq R, Kaufman HL. Clinical landscape of oncoIytic virus research in 2020. J Immunother Cancer. 2020;8(2):e001486.

8. Cao GD, He XB, Sun Q, Chen S, Wan K, Xu X, Feng X, Li PP, Chen B, Xiong $\mathrm{MM}$. The oncolytic virus in cancer diagnosis and treatment. Front Oncol. 2020;10:1786.

9. Farrera-Sal M, Moya-Borrego L, Bazan-Peregrino M, Alemany R. Evolving status of clinical immunotherapy with oncolytic adenovirus. Clin Cancer Res Off J Am Assoc Cancer Res. 2021.

10. Hemminki O, Dos Santos JM, Hemminki A. Oncolytic viruses for cancer immunotherapy. J Hematol Oncol. 2020;13(1):84.

11. Peter M, Kuhnel F. Oncolytic adenovirus in cancer immunotherapy. Cancers. 2020;12(11):3354. 
12. Ruano D, Lopez-Martin JA, Moreno L, Lassaletta A, Bautista F, Andion M, Hernandez C, Gonzalez-Murillo A, Melen G, Alemany R, et al. Firstin-human, first-in-child trial of autologous MSCs carrying the oncolytic virus Icovir-5 in patients with advanced tumors. Mol Therapy J Am Soc Gene Therapy. 2020;28(4):1033-42.

13. Machiels JP, Salazar R, Rottey S, Duran I, Dirix L, Geboes K, WilkinsonBlanc C, Pover G, Alvis S, Champion B, et al. A phase 1 dose escalation study of the oncolytic adenovirus enadenotucirev, administered intravenously to patients with epithelial solid tumors (EVOLVE). J Immunother Cancer. 2019;7(1):20.

14. Small EJ, Carducci MA, Burke JM, Rodriguez R, Fong L, van Ummersen L, Yu DC, Aimi J, Ando D, Working P, et al. A phase I trial of intravenous CG7870, a replication-selective, prostate-specific antigen-targeted oncolytic adenovirus, for the treatment of hormone-refractory, metastatic prostate cancer. Mol Therapy J Am Soc Gene Therapy. 2006;14(1):107-17.

15. Sin J, Mangale V, Thienphrapa W, Gottlieb RA, Feuer R. Recent progress in understanding coxsackievirus replication, dissemination, and pathogenesis. Virology. 2015;484:288-304.

16. Bradley S, Jakes AD, Harrington $K$, Pandha $H$, Melcher $A$, Errington-Mais F. Applications of coxsackievirus A21 in oncology. Oncolytic Virotherapy. 2014;3:47-55

17. McCarthy C, Jayawardena N, Burga LN, Bostina M. Developing picornaviruses for cancer therapy. Cancers. 2019;11(5):685.

18. Koch MS, Lawler SE, Chiocca EA. HSV-1 oncolytic viruses from bench to bedside: an overview of current clinical trials. Cancers. 2020;12(12):3514.

19. Menotti L, Avitabile E. Herpes simplex virus oncolytic immunovirotherapy: the blossoming branch of multimodal therapy. Int J Mol Sci. 2020;21(21):8310.

20. Xu X, Zhang Y, Li Q. Characteristics of herpes simplex virus infection and pathogenesis suggest a strategy for vaccine development. Rev Med Virol. 2019;29(4):e2054.

21. Andtbacka RH, Kaufman HL, Collichio F, Amatruda T, Senzer N, Chesney J, Delman KA, Spitler LE, Puzanov I, Agarwala SS, et al. Talimogene laherparepvec improves durable response rate in patients with advanced melanoma. J Clin Oncol Off J Am Soc Clin Oncol. 2015;33(25):2780-8.

22. Breitbach CJ. Considerations for clinical translation of MG1 Maraba virus. Methods Mol Biol. 2020;2058:285-93.

23. Pol JG, Atherton MJ, Bridle BW, Stephenson KB, Le Boeuf F, Hummel JL, Martin CG, Pomoransky J, Breitbach CJ, Diallo JS, et al. Development and applications of oncolytic Maraba virus vaccines. Oncolytic Virotherapy. 2018;7:117-28.

24. Zemp F, Rajwani J, Mahoney DJ. Rhabdoviruses as vaccine platforms for infectious disease and cancer. Biotechnol Genet Eng Rev. 2018;34(1):122-38.

25. Engeland CE, Ungerechts $G$. Measles virus as an oncolytic immunotherapy. Cancers. 2021;13(3):544

26. Pidelaserra-Marti G, Engeland CE. Mechanisms of measles virus oncolytic immunotherapy. Cytokine Growth Factor Rev. 2020;56:28-38.

27. Leber MF, Neault S, Jirovec E, Barkley R, Said A, Bell JC, Ungerechts G. Engineering and combining oncolytic measles virus for cancer therapy. Cytokine Growth Factor Rev. 2020;56:39-48.

28. Msaouel P, Opyrchal M, Dispenzieri A, Peng KW, Federspiel MJ, Russell SJ, Galanis E. Clinical trials with oncolytic measles virus: current status and future prospects. Curr Cancer Drug Targets. 2018;18(2):177-87.

29. Aref S, Bailey K, Fielding A. Measles to the rescue: a review of oncolytic measles virus. Viruses. 2016;8(10):294.

30. Packiriswamy N, Upreti D, Zhou Y, Khan R, Miller A, Diaz RM, Rooney CM, Dispenzieri A, Peng KW, Russell SJ. Oncolytic measles virus therapy enhances tumor antigen-specific T-cell responses in patients with multiple myeloma. Leukemia. 2020;34(12):3310-22

31. Angelova A, Ferreira T, Bretscher C, Rommelaere J, Marchini A. Parvovirus-based combinatorial immunotherapy: a reinforced therapeutic strategy against poor-prognosis solid cancers. Cancers. 2021;13(2):342.

32. Hartley A, Kavishwar G, Salvato I, Marchini A. A roadmap for the success of oncolytic parvovirus-based anticancer therapies. Annu Rev Virol. 2020;7(1):537-57

33. Bretscher C, Marchini A. H-1 parvovirus as a cancer-killing agent: past, present, and future. Viruses. 2019;11(6):562
34. Ferreira T, Kulkarni A, Bretscher C, Richter K, Ehrlich M, Marchini A Oncolytic $\mathrm{H}-1$ parvovirus enters cancer cells through clathrin-mediated endocytosis. Viruses. 2020;12(10):1199.

35. Geletneky K, Huesing J, Rommelaere J, Schlehofer JR, Leuchs B, Dahm M, Krebs O, von Knebel DM, Huber B, Hajda J. Phase I/Ila study of intratumoral/intracerebral or intravenous/intracerebral administration of Parvovirus $\mathrm{H}-1$ (ParvOryx) in patients with progressive primary or recurrent glioblastoma multiforme: ParvOryx01 protocol. BMC Cancer. 2012;12:99.

36. Geletneky K, Hajda J, Angelova AL, Leuchs B, Capper D, Bartsch AJ, Neumann JO, Schoning T, Husing J, Beelte B, et al. Oncolytic $\mathrm{H}-1$ parvovirus shows safety and signs of immunogenic activity in a first phase I/lla glioblastoma trial. Mol Ther J Am Soc Gene Ther. 2017;25(12):2620-34.

37. Hajda J, Lehmann M, Krebs O, Kieser M, Geletneky K, Jager D, Dahm M, Huber B, Schoning T, Sedlaczek $O$, et al. A non-controlled, single arm, open label, phase II study of intravenous and intratumoral administration of ParvOryx in patients with metastatic, inoperable pancreatic cancer: ParvOryx02 protocol. BMC Cancer. 2017;17(1):576.

38. Gromeier M, Nair SK. Recombinant poliovirus for cancer immunotherapy. Annu Rev Med. 2018;69:289-99.

39. Desjardins A, Gromeier M, Herndon JE 2nd, Beaubier N, Bolognesi DP, Friedman AH, Friedman HS, McSherry F, Muscat AM, Nair S, et al. Recurrent glioblastoma treated with recombinant poliovirus. N Engl J Med. 2018;379(2):150-61.

40. McNamara A, Roebke K, Danthi P. Cell killing by reovirus: mechanisms and consequences. Curr Top Microbiol Immunol. 2020.

41. Muller L, Berkeley R, Barr T, Ilett E, Errington-Mais F. Past, present and future of oncolytic reovirus. Cancers. 2020;12(11):3219.

42. Zhang Z, Dong L, Zhao C, Zheng P, Zhang X, Xu J. Vaccinia virus-based vector against infectious diseases and tumors. Hum Vaccin Immunother. 2021:1:8.

43. Pelin A, Boulton S, Tamming LA, Bell JC, Singaravelu R. Engineering vaccinia virus as an immunotherapeutic battleship to overcome tumor heterogeneity. Expert Opin Biol Ther. 2020;20(9):1083-97.

44. Torres-Dominguez LE, McFadden G. Poxvirus oncolytic virotherapy. Expert Opin Biol Ther. 2019;19(6):561-73.

45. Kretzschmar M, Wallinga J, Teunis $P$, Xing S, Mikolajczyk R. Frequency of adverse events after vaccination with different vaccinia strains. PLoS Med. 2006;3(8):e272.

46. Isaacs SN. Working safely with vaccinia virus: laboratory technique and review of published cases of accidental laboratory infections with poxviruses. Methods Mol Biol. 2019:2023:1-27.

47. Silva NIO, de Oliveira JS, Kroon EG, Trindade GS, Drumond BP. Here, there, and everywhere: the wide host range and geographic distribution of zoonotic orthopoxviruses. Viruses. 2020;13(1):43.

48. Miest TS, Cattaneo R. New viruses for cancer therapy: meeting clinical needs. Nat Rev Microbiol. 2014;12(1):23-34.

49. Seymour LW, Fisher KD. Oncolytic viruses: finally delivering. Br J Cancer. 2016;114(4):357-61.

50. Russell SJ, Peng KW, Bell JC. Oncolytic virotherapy. Nat Biotechnol. 2012;30(7):658-70.

51. Ilkow CS, Marguerie M, Batenchuk C, Mayer J, Ben Neriah D, Cousineau S, Falls T, Jennings VA, Boileau M, Bellamy D, et al. Reciprocal cellular cross-talk within the tumor microenvironment promotes oncolytic virus activity. Nat Med. 2015;21(5):530-6.

52. Arulanandam R, Batenchuk C, Angarita FA, Ottolino-Perry K, Cousineau S, Mottashed A, Burgess E, Falls TJ, De Silva N, Tsang J, et al. VEGFmediated induction of PRD1-BF1/Blimp1 expression sensitizes tumor vasculature to oncolytic virus infection. Cancer Cell. 2015;28(2):210-24.

53. Breitbach CJ, De Silva NS, Falls TJ, Aladl U, Evgin L, Paterson J, Sun YY, Roy DG, Rintoul JL, Daneshmand M, et al. Targeting tumor vasculature with an oncolytic virus. Mol Ther J Am Soc Gene Ther. 2011;19(5):886-94.

54. Lichty BD, Breitbach CJ, Stojdl DF, Bell JC. Going viral with cancer immunotherapy. Nat Rev Cancer. 2014;14(8):559-67.

55. Achard C, Surendran A, Wedge ME, Ungerechts G, Bell J, Ilkow CS. Lighting a fire in the tumor microenvironment using oncolytic immunotherapy. EBioMedicine. 2018;31:17-24.

56. Pol JG, Workenhe ST, Konda P, Gujar S, Kroemer G. Cytokines in oncoIytic virotherapy. Cytokine Growth Factor Rev. 2020 
57. Twumasi-Boateng K, Pettigrew JL, Kwok YYE, Bell JC, Nelson BH. Oncolytic viruses as engineering platforms for combination immunotherapy. Nat Rev Cancer. 2018;18(7):419-32.

58. Oh CM, Chon HJ, Kim C. Combination immunotherapy using oncolytic virus for the treatment of advanced solid tumors. Int J Mol Sci. 2020;21(20):7743.

59. Shi T, Song $X$, Wang $Y$, Liu F, Wei J. Combining oncolytic viruses with cancer immunotherapy: establishing a new generation of cancer treatment. Front Immunol. 2020;11:683.

60. Ribas A, Dummer R, Puzanov I, VanderWalde A, Andtbacka RHI, Michielin O, Olszanski AJ, Malvehy J, Cebon J, Fernandez E, et al. Oncolytic virotherapy promotes intratumoral T cell infiltration and improves antiPD-1 immunotherapy. Cell. 2017:170(6):1109-1119.e1110.

61. Samson A, Scott KJ, Taggart D, West EJ, Wilson E, Nuovo GJ, Thomson S, Corns R, Mathew RK, Fuller MJ, et al. Intravenous delivery of oncolytic reovirus to brain tumor patients immunologically primes for subsequent checkpoint blockade. Sci Transl Med. 2018;10(422):eaam7577

62. Bourgeois-Daigneault MC, Roy DG, Aitken AS, El Sayes N, Martin NT, Varette O, Falls T, St-Germain LE, Pelin A, Lichty BD, et al. Neoadjuvant oncolytic virotherapy before surgery sensitizes triple-negative breast cancer to immune checkpoint therapy. Sci Transl Med. 2018;10(422):eaao1641.

63. Haitz K, Khosravi H, Lin JY, Menge T, Nambudiri VE. Review of talimogene laherparepvec: a first-in-class oncolytic viral treatment of advanced melanoma. J Am Acad Dermatol. 2020;83(1):189-96.

64. van Akkooi ACJ, Haferkamp S, Papa S, Franke V, Pinter A, Weishaupt C, Huber MA, Loquai C, Richtig E, Gokani P, et al. A retrospective chart review study of real-world use of talimogene laherparepvec in unresectable stage IIIB-IVM1a melanoma in four European countries. Adv Ther. 2021;38(2):1245-62.

65. Galanis E, Atherton PJ, Maurer MJ, Knutson KL, Dowdy SC, Cliby WA Haluska P Jr, Long HJ, Oberg A, Aderca I, et al. Oncolytic measles virus expressing the sodium iodide symporter to treat drug-resistant ovarian cancer. Can Res. 2015;75(1):22-30.

66. Larocca CA, LeBoeuf NR, Silk AW, Kaufman HL. An update on the role of talimogene laherparepvec (T-VEC) in the treatment of melanoma: best practices and future directions. Am J Clin Dermatol. 2020;21(6):821-32.

67. Song X-T. Combination of virotherapy and T-cell therapy: arming oncoIytic virus with T-cell engagers. Discov Med. 2013;16(90):261-6.

68. Scott EM, Duffy MR, Freedman JD, Fisher KD, Seymour LW. Solid tumor immunotherapy with T cell engager-armed oncolytic viruses. Macromol Biosci. 2018;18(1):1700187

69. Guo ZS, Lotze MT, Zhu Z, Storkus WJ, Song XT. Bi- and tri-specific T cell engager-armed oncolytic viruses: next-generation cancer immunotherapy. Biomedicines. 2020;8(7):204.

70. Yu F, Wang X, Guo ZS, Bartlett DL, Gottschalk SM, Song XT. T-cell engager-armed oncolytic vaccinia virus significantly enhances antitumor therapy. Mol Ther J Am Soc Gene Ther. 2014;22(1):102-11.

71. Coffman KT, Hu M, Carles-Kinch K, Tice D, Donacki N, Munyon K, Kifle G, Woods R, Langermann S, Kiener PA, et al. Differential EphA2 epitope display on normal versus malignant cells. Can Res. 2003;63(22):7907-12.

72. Albelda SM, Thorne SH. Giving oncolytic vaccinia virus more BiTE. Mol Ther J Am Soc Gene Ther. 2014;22(1):6-8

73. Fajardo CA, Guedan S, Rojas LA, Moreno R, Arias-Badia M, de Sostoa J, June $\mathrm{CH}$, Alemany R. Oncolytic adenoviral delivery of an EGFRtargeting T-cell engager improves antitumor efficacy. Can Res. 2017;77(8):2052-63.

74. Barlabé P, Sostoa J, Fajardo CA, Alemany R, Moreno R. Enhanced antitumor efficacy of an oncolytic adenovirus armed with an EGFR-targeted BiTE using menstrual blood-derived mesenchymal stem cells as carriers. Cancer Gene Ther. 2020;27(5):383-8.

75. Moreno R, Fajardo CA, Farrera-Sal M, Perisé-Barrios AJ, Morales-Molina A, Al-Zaher AA, García-Castro J, Alemany R. Enhanced antitumor efficacy of oncolytic adenovirus-loaded menstrual blood-derived mesenchymal stem cells in combination with peripheral blood mononuclear cells. Mol Cancer Ther. 2019;18(1):127-38.

76. Moreno R, Rojas LA, Villellas FV, Soriano VC, García-Castro J, Fajardo CA, Alemany R. Human menstrual blood-derived mesenchymal stem cells as potential cell carriers for oncolytic adenovirus. Stem Cells Int 2017; 2017:3615729
77. Freedman JD, Hagel J, Scott EM, Psallidas I, Gupta A, Spiers L, Miller $P$, Kanellakis N. Oncolytic adenovirus expressing bispecific antibody targets T-cell cytotoxicity in cancer biopsies. EMBO Mol Med. 2017;9(8):1067-87.

78. Gires O, Pan M, Schinke H, Canis M, Baeuerle PA. Expression and function of epithelial cell adhesion molecule EpCAM: where are we after 40 years? Cancer Metastasis Rev. 2020;39(3):969-87.

79. Scott EM, Frost S, Khalique H, Freedman JD, Seymour LW, Lei-Rossmann J. Use of liquid patient ascites fluids as a preclinical model for oncolytic virus activity. Methods Mol Biol. 2020;2058:261-70.

80. Garcia-Carbonero R, Salazar R, Duran I, Osman-Garcia I, Paz-Ares L, Bozada JM, Boni V, Blanc C, Seymour L, Beadle J, et al. Phase 1 study of intravenous administration of the chimeric adenovirus enadenotucirev in patients undergoing primary tumor resection. J Immunother Cancer. 2017;5(1):71.

81. Illingworth S, Di Y, Bauzon M, Lei J, Duffy MR, Alvis S, Champion B, Lieber A, Hermiston T, Seymour LW, et al. Preclinical safety studies of enadenotucirev, a chimeric group B human-specific oncolytic adenovirus. Mol Ther Oncolytics. 2017;5:62-74.

82. Speck T, Heidbuechel JPW, Veinalde R, Jaeger D, von Kalle C, Ball CR, Ungerechts G, Engeland CE. Targeted BiTE expression by an oncolytic vector augments therapeutic efficacy against solid tumors. Clin Cancer Res Off J Am Assoc Cancer Res. 2018;24:2128-37.

83. Heidbuechel JPW, Engeland CE. Paramyxoviruses for tumortargeted immunomodulation: design and evaluation ex vivo. JoVE. 2019;143:e58651.

84. Engeland CE, Grossardt C, Veinalde R, Bossow S, Lutz D, Kaufmann JK, Shevchenko I, Umansky V, Nettelbeck DM, Weichert W, et al. CTLA-4 and PD-L1 checkpoint blockade enhances oncolytic measles virus therapy. Mol Ther J Am Soc Gene Ther. 2014;22(11):1949-59.

85. Hardcastle J, Mills L, Malo CS, Jin F, Kurokawa C, Geekiyanage H, Schroeder M, Sarkaria J, Johnson AJ, Galanis E. Immunovirotherapy with measles virus strains in combination with anti-PD-1 antibody blockade enhances antitumor activity in glioblastoma treatment. Neuro Oncol. 2017:19(4):493-502.

86. Wing A, Fajardo CA, Posey AD Jr, Shaw C, Da T, Young RM, Alemany R, June $\mathrm{CH}$, Guedan S. Improving CART-cell therapy of solid tumors with oncolytic virus-driven production of a bispecific T-cell engager. Cancer Immunol Res. 2018;6(5):605-16.

87. June $\mathrm{CH}$, Sadelain M. Chimeric antigen receptor therapy. N Engl J Med. 2018;379(1):64-73.

88. Frigault MJ, Maus MV. State of the art in CART cell therapy for CD19+ B cell malignancies. J Clin Investig. 2020;130(4):1586-94.

89. Subklewe M. BiTEs better than CART cells. Blood Adv. 2021;5(2):607-12.

90. Molina JC, Shah NN. CART cells better than BiTEs. Blood Adv. 2021;5(2):602-6.

91. Slaney CY, Wang P, Darcy PK, Kershaw MH. CARs versus BiTEs: a comparison between T cell-redirection strategies for cancer treatment. Cancer Discov. 2018;8(8):924-34.

92. Ajina A, Maher J. Prospects for combined use of oncolytic viruses and CAR T-cells. J Immunother Cancer. 2017;5(1):90.

93. Guedan S, Alemany R. CAR-T cells and oncolytic viruses: joining forces to overcome the solid tumor challenge. Front Immunol. 2018:9:2460.

94. Porter CE, Rosewell Shaw A, Jung Y, Yip T, Castro PD, Sandulache VC, Sikora A, Gottschalk S, Ittman MM, Brenner MK, et al. Oncolytic adenovirus armed with BiTE, Cytokine, and checkpoint inhibitor enables CAR $T$ cells to control the growth of heterogeneous tumors. Mol Ther J Am Soc Gene Ther. 2020;28(5):1251-62.

95. Farzad L, Cerullo V, Yagyu S, Bertin T, Hemminki A, Rooney C, Lee B, Suzuki M. Combinatorial treatment with oncolytic adenovirus and helper-dependent adenovirus augments adenoviral cancer gene therapy. Mol Ther Oncolytics. 2014;1:14008.

96. Rosewell Shaw A, Porter CE, Watanabe N, Tanoue K, Sikora A, Gottschalk S, Brenner MK, Suzuki M. Adenovirotherapy delivering cytokine and checkpoint inhibitor augments CART cells against metastatic head and neck cancer. Mol Ther J Am Soc Gene Ther. 2017;25(11):2440-51.

97. Tanoue K, Rosewell Shaw A, Watanabe N, Porter C, Rana B, Gottschalk S, Brenner M, Suzuki M. Armed oncolytic adenovirus-expressing PD-L1 mini-body enhances antitumor effects of chimeric antigen receptor T cells in solid tumors. Can Res. 2017;77(8):2040-51. 
98. Rupp U, Schoendorf-Holland E, Eichbaum M, Schuetz F, Lauschner I, Schmidt P, Staab A, Hanft G, Huober J, Sinn HP, et al. Safety and pharmacokinetics of bivatuzumab mertansine in patients with CD44v6-positive metastatic breast cancer: final results of a phase I study. Anticancer Drugs. 2007;18(4):477-85.

99. Casucci M, Nicolis di Robilant B, Falcone L, Camisa B, Norelli M, Genovese P, Gentner B, Gullotta F, Ponzoni M, Bernardi M, et al. CD44v6-targeted $T$ cells mediate potent antitumor effects against acute myeloid leukemia and multiple myeloma. Blood. 2013;122(20):3461-72.

100. Hegde PS, Chen DS. Top 10 challenges in cancer immunotherapy. Immunity. 2020;52(1):17-35.

101. Yu F, Hong B, Song X-T. A T-cell engager-armed oncolytic vaccinia virus to target the tumor stroma. Cancer TransI Med. 2017;3(4):122-32.

102. Chen X, Song E. Turning foes to friends: targeting cancer-associated fibroblasts. Nat Rev Drug Discov. 2019;18(2):99-115.

103. Everts A, Bergeman M, McFadden G, Kemp V. Simultaneous tumor and stroma targeting by oncolytic viruses. Biomedicines. 2020;8(11):474.

104. Levy MT, McCaughan GW, Abbott CA, Park JE, Cunningham AM, Müller E, Rettig WJ, Gorrell MD. Fibroblast activation protein: a cell surface dipeptidyl peptidase and gelatinase expressed by stellate cells at the tissue remodelling interface in human cirrhosis. Hepatology (Baltimore, MD). 1999;29(6):1768-78.

105. Jacob M, Chang L, Puré E. Fibroblast activation protein in remodeling tissues. Curr Mol Med. 2012;12(10):1220-43.

106. Freedman JD, Duffy MR, Lei-Rossmann J, Muntzer A, Scott EM, Hagel J, Campo L, Bryant RJ, Verrill C, Lambert A, et al. An oncolytic virus expressing a T-cell engager simultaneously targets cancer and immunosuppressive stromal cells. Cancer Res. 2018;24:6852.

107. de Sostoa J, Fajardo CA, Moreno R, Ramos MD, Farrera-Sal M, Alemany R. Targeting the tumor stroma with an oncolytic adenovirus secreting a fibroblast activation protein-targeted bispecific T-cell engager. J Immunother Cancer. 2019;7(1):19.

108. Scott EM, Jacobus EJ, Lyons B, Frost S, Freedman JD, Dyer A, Khalique $H$, Taverner WK, Carr A, Champion BR, et al. Bi- and tri-valent T cell engagers deplete tumour-associated macrophages in cancer patient samples. J Immunother Cancer. 2019;7(1):320.

109. Hamers-Casterman C, Atarhouch T, Muyldermans S, Robinson G, Hamers C, Songa EB, Bendahman N, Hamers R. Naturally occurring antibodies devoid of light chains. Nature. 1993;363(6428):446-8.

110. Greenberg AS, Avila D, Hughes M, Hughes A, McKinney EC, Flajnik MF. A new antigen receptor gene family that undergoes rearrangement and extensive somatic diversification in sharks. Nature. 1995;374(6518):168-73.

111. Muyldermans S. Nanobodies: natural single-domain antibodies. Annu Rev Biochem. 2013;82:775-97.

112. Wang K, Wei G, Liu D. CD19: a biomarker for B cell development, lymphoma diagnosis and therapy. Exp Hematol Oncol. 2012;1(1):36.

113. Neelapu SS. Managing the toxicities of CART-cell therapy. Hematol Oncol. 2019;37(Suppl 1):48-52.

114. Salmaninejad A, Zamani MR, Pourvahedi M, Golchehre Z, Hosseini Bereshneh A, Rezaei N. Cancer/testis antigens: expression, regulation, tumor invasion, and use in immunotherapy of cancers. Immunol Invest. 2016:45(7):619-40.

115. Gordeeva O. Cancer-testis antigens: unique cancer stem cell biomarkers and targets for cancer therapy. Semin Cancer Biol. 2018;53:75-89.

116. Schumacher TN, Scheper W, Kvistborg P. Cancer neoantigens. Annu Rev Immunol. 2019;37:173-200.

117. Haen SP, Löffler MW, Rammensee HG, Brossart P. Towards new horizons: characterization, classification and implications of the tumour antigenic repertoire. Nat Rev Clin Oncol. 2020;17(10):595-610.

118. Vigneron N. Human tumor antigens and cancer immunotherapy. Biomed Res Int. 2015;2015:948501

119. Fisher K, Hazini A, Seymour LW. Tackling HLA deficiencies head on with oncolytic viruses. Cancers. 2021;13(4):719.

120. Baker AT, Aguirre-Hernández C, Halldén G, Parker AL. Designer oncolytic adenovirus: coming of age. Cancers. 2018;10(6):201.

121. Guo ZS, Lu B, Guo Z, Giehl E, Feist M, Dai E, Liu W, Storkus WJ, He Y, Liu Z, et al. Vaccinia virus-mediated cancer immunotherapy: cancer vaccines and oncolytics. J Immunother Cancer. 2019;7(1):6.

122. Transgene provides update on PHOCUS study of Pexa-Vec in liver cancer following planned interim futility analysis. https://www.businesswi
re.com/news/home/20190802005141/en/Transgene-Provides-Updateon-PHOCUS-Study-of-Pexa-Vec-in-Liver-Cancer-Following-PlannedInterim-Futility-Analysis.

123. Russell SJ, Peng KW. Measles virus for cancer therapy. Curr Top Microbiol Immunol. 2009;330:213-41.

124. Mühlebach MD. Measles virus in cancer therapy. Curr Opin Virol. 2020;41:85-97.

125. Langfield KK, Walker HJ, Gregory LC, Federspiel MJ. Manufacture of measles viruses. Methods Mol Biol. 2011:737:345-66.

126. Loewe D, Dieken H, Grein TA, Weidner T, Salzig D, Czermak P. Opportunities to debottleneck the downstream processing of the oncolytic measles virus. Crit Rev Biotechnol. 2020;40(2):247-64.

127. Russell SJ, Federspiel MJ, Peng KW, Tong C, Dingli D, Morice WG, Lowe V, O'Connor MK, Kyle RA, Leung N, et al. Remission of disseminated cancer after systemic oncolytic virotherapy. Mayo Clin Proc. 2014;89(7):926-33.

128. Groeneveldt C, Kinderman P, van den Wollenberg DJM, van den Oever RL, Middelburg J, Mustafa DAM, Hoeben RC, van der Burg SH, van Hall T, van Montfoort N. Preconditioning of the tumor microenvironment with oncolytic reovirus converts CD3-bispecific antibody treatment into effective immunotherapy. J Immunother Cancer. 2020;8(2):e001191.

129. Kemp V, Lamfers MLM, van der Pluijm G, van den Hoogen BG, Hoeben RC. Developing oncolytic viruses for clinical use: a consortium approach. Cytokine Growth Factor Rev. 2020;56:133-40.

130. Cervera-Carrascon V, Quixabeira DCA, Havunen R, Santos JM, Kutvonen E, Clubb JHA, Siurala M, Heiniö C, Zafar S, Koivula T, et al. Comparison of clinically relevant oncolytic virus platforms for enhancing $T$ cell therapy of solid tumors. Mol Ther Oncolytics. 2020;17:47-60.

131. Ferguson MS, Lemoine NR, Wang Y. Systemic delivery of oncolytic viruses: hopes and hurdles. Adv Virol. 2012;2012:805629.

132. Hill C, Carlisle R. Achieving systemic delivery of oncolytic viruses. Expert Opin Drug Deliv. 2019;16(6):607-20.

133. Liu BL, Robinson M, Han ZQ, Branston RH, English C, Reay P, McGrath Y, Thomas SK, Thornton M, Bullock P, et al. ICP34.5 deleted herpes simplex virus with enhanced oncolytic, immune stimulating, and anti-tumour properties. Gene Ther. 2003;10(4):292-303.

134. Dias JD, Hemminki O, Diaconu I, Hirvinen M, Bonetti A, Guse K, Escutenaire S, Kanerva A, Pesonen S, Loskog A, et al. Targeted cancer immunotherapy with oncolytic adenovirus coding for a fully human monoclonal antibody specific for CTLA-4. Gene Ther. 2012;19(10):988-98.

135. Robbins PF, Kassim SH, Tran TL, Crystal JS, Morgan RA, Feldman SA, Yang JC, Dudley ME, Wunderlich JR, Sherry RM, et al. A pilot trial using lymphocytes genetically engineered with an NY-ESO-1-reactive T-cell receptor: long-term follow-up and correlates with response. Clin Cancer Res Off J Am Assoc Cancer Res. 2015;21(5):1019-27.

136. Baeuerle PA, Ding J, Patel E, Thorausch N, Horton H, Gierut J, Scarfo I, Choudhary R, Kiner O, Krishnamurthy J, et al. Synthetic TRuC receptors engaging the complete $\mathrm{T}$ cell receptor for potent anti-tumor response. Nat Commun. 2019;10(1):2087.

137. Iwahori K, Kakarla S, Velasquez MP, Yu F, Yi Z, Gerken C, Song XT, Gottschalk S. Engager T cells: a new class of antigen-specific $T$ cells that redirect bystander T cells. Mol Ther J Am Soc Gene Ther. 2015;23(1):171-8.

138. Choi BD, Yu X, Castano AP, Bouffard AA, Schmidts A, Larson RC, Bailey SR, Boroughs AC, Frigault MJ, Leick MB, et al. CAR-T cells secreting BiTEs circumvent antigen escape without detectable toxicity. Nat Biotechnol. 2019;37(9):1049-58.

139. Park AK, Fong Y, Kim SI, Yang J, Murad JP, Lu J, Jeang B, Chang WC, Chen $\mathrm{NG}$, Thomas $\mathrm{SH}$, et al. Effective combination immunotherapy using oncolytic viruses to deliver CAR targets to solid tumors. Sci Transl Med. 2020;12(559):eaaz1863.

140. Zamarin D, Holmgaard RB, Subudhi SK, Park JS, Mansour M, Palese P, Merghoub T, Wolchok JD, Allison JP. Localized oncolytic virotherapy overcomes systemic tumor resistance to immune checkpoint blockade immunotherapy. Sci Transl Med. 2014;6(226):226-32.

141. Gardell JL, Matsumoto LR, Chinn H, DeGolier KR, Kreuser SA, Prieskorn B, Balcaitis S, Davis A, Ellenbogen RG, Crane CA. Human macrophages engineered to secrete a bispecific $T$ cell engager support antigendependent T cell responses to glioblastoma. J Immunother Cancer. 2020;8(2):e001202.

142. Li M, Li G, Kiyokawa J, Tirmizi Z, Richardson LG, Ning J, Das S, Martuza RL, Stemmer-Rachamimov A, Rabkin SD, et al. Characterization and 
oncolytic virus targeting of FAP-expressing tumor-associated pericytes in glioblastoma. Acta Neuropathol Commun. 2020;8(1):221.

143. Jamieson TR, Poutou J, Ilkow CS. Redirecting oncolytic viruses: engineering opportunists to take control of the tumour microenvironment. Cytokine Growth Factor Rev. 2020;56:102-14.

144. Matuszewska K, Santry LA, van Vloten JP, AuYeung AWK, Major PP, Lawler J, Wootton SK, Bridle BW, Petrik J. Combining vascular normalization with an oncolytic virus enhances immunotherapy in a preclinical model of advanced-stage ovarian cancer. Clin Cancer Res Off J Am Assoc Cancer Res. 2019;25(5):1624-38.

145. Meng G, Li B, Chen A, Zheng M, Xu T, Zhang H, Dong J, Wu J, Yu D, Wei J. Targeting aerobic glycolysis by dichloroacetate improves Newcastle disease virus-mediated viro-immunotherapy in hepatocellular carcinoma. Br J Cancer. 2020;122(1):111-20.

146. Katayama Y, Tachibana M, Kurisu N, Oya Y, Terasawa Y, Goda H, Kobiyama K, Ishii KJ, Akira S, Mizuguchi H, et al. Oncolytic reovirus inhibits immunosuppressive activity of myeloid-derived suppressor cells in a TLR3-dependent manner. J Immunol (Baltimore, Md: 1950). 2018;200(8):2987-99.

147. Ding AS, Routkevitch D, Jackson C, Lim M. Targeting myeloid cells in combination treatments for glioma and other tumors. Front Immunol. 2019;10:1715.

148. Bach P, Abel T, Hoffmann C, Gal Z, Braun G, Voelker I, Ball CR, Johnston IC, Lauer UM, Herold-Mende C, et al. Specific elimination of CD133+ tumor cells with targeted oncolytic measles virus. Can Res. 2013;73(2):865-74.

149. Crupi MJF, Bell JC, Singaravelu R. Concise review: targeting cancer stem cells and their supporting niche using oncolytic viruses. Stem Cells. 2019;37:716.

150. Santiago DN, Heidbuechel JPW, Kandell WM, Walker R, Djeu J, Engeland $\mathrm{CE}$, Abate-Daga D, Enderling H. Fighting cancer with mathematics and viruses. Viruses. 2017;9(9):239.
151. Heidbuechel JPW, Abate-Daga D, Engeland CE, Enderling H. Mathematical modeling of oncolytic virotherapy. Methods Mol Biol. 2020:2058:307-20.

152. Wodarz D. Computational modeling approaches to the dynamics of oncolytic viruses. Wiley Interdiscip Rev Syst Biol Med. 2016;8(3):242-52.

153. Wodarz D, Hofacre A, Lau JW, Sun Z, Fan H, Komarova NL. Complex spatial dynamics of oncolytic viruses in vitro: mathematical and experimental approaches. PLoS Comput Biol. 2012;8(6):e1002547.

154. Ungerechts G, Bossow S, Leuchs B, Holm PS, Rommelaere J, Coffey M, Coffin R, Bell J, Nettelbeck DM. Moving oncolytic viruses into the clinic: clinical-grade production, purification, and characterization of diverse oncolytic viruses. Mol Therapy Methods Clin Dev. 2016;3:16018.

155. Barkholt L, Voltz-Girolt C, Raine J, Salmonson T, Schüssler-Lenz M. Regulatory watch: European regulatory experience with advanced therapy medicinal products. Nat Rev Drug Discovery. 2019;18(1):8-9.

156. Ausubel LJ, Meseck M, Derecho I, Lopez P, Knoblauch C, McMahon R, Anderson J, Dunphy N, Quezada V, Khan R, et al. Current good manufacturing practice production of an oncolytic recombinant vesicular stomatitis viral vector for cancer treatment. Hum Gene Ther. 2011;22(4):489-97.

157. Grein TA, Loewe D, Dieken H, Weidner T, Salzig D, Czermak P. Aeration and shear stress are critical process parameters for the production of oncolytic measles virus. Front Bioeng Biotechnol. 2019;7:78.

158. Hartmann J, Schussler-Lenz M, Bondanza A, Buchholz CJ. Clinical development of CART cells-challenges and opportunities in translating innovative treatment concepts. EMBO Mol Med. 2017;9(9):1183-97.

\section{Publisher's Note}

Springer Nature remains neutral with regard to jurisdictional claims in published maps and institutional affiliations.
Ready to submit your research? Choose BMC and benefit from:

- fast, convenient online submission

- thorough peer review by experienced researchers in your field

- rapid publication on acceptance

- support for research data, including large and complex data types

- gold Open Access which fosters wider collaboration and increased citations

- maximum visibility for your research: over $100 \mathrm{M}$ website views per year

At BMC, research is always in progress.

Learn more biomedcentral.com/submissions 